Review

\title{
A Review of DC Microgrid Energy Management Systems Dedicated to Residential Applications
}

\author{
Sadaqat Ali ${ }^{1, *}$, Zhixue Zheng ${ }^{1, *(\mathbb{D},}$, Michel Aillerie ${ }^{1, *(\mathbb{D}}$, Jean-Paul Sawicki ${ }^{1}$, Marie-Cécile Péra ${ }^{2,3}$ and \\ Daniel Hissel 2,3 (D)
}

check for updates

Citation: Ali, S.; Zheng, Z.; Aillerie, M.; Sawicki, J.-P.; Péra, M.-C.; Hissel, D. A Review of DC Microgrid Energy Management Systems Dedicated to Residential Applications. Energies 2021, 14, 4308. https://doi.org/ $10.3390 /$ en 14144308

Academic Editor: Neville R. Watson

Received: 9 June 2021

Accepted: 14 July 2021

Published: 17 July 2021

Publisher's Note: MDPI stays neutral with regard to jurisdictional claims in published maps and institutional affiliations.

Copyright: (c) 2021 by the authors. Licensee MDPI, Basel, Switzerland. This article is an open access article distributed under the terms and conditions of the Creative Commons Attribution (CC BY) license (https:// creativecommons.org/licenses/by/ $4.0 /)$.
1 Laboratoire Matériaux Optiques, Photonique et Systèmes (LMOPS), Université de Lorraine, CentraleSupélec, F-57000 Metz, France; jean-paul.sawicki@univ-lorraine.fr

2 Centre National de la Recherche Scientifique (CNRS), Franche-Comté Électronique Mécanique Thermique et Optique-Sciences et Technologies (FEMTO-ST) Institute, Université Bourgogne Franche-Comté, F-90010 Belfort, France; marie-cecile.pera@univ-fcomte.fr (M.-C.P.); daniel.hissel@univ-fcomte.fr (D.H.)

3 FCLAB, Centre National de la Recherche Scientifique (CNRS), F-90010 Belfort, France

* Correspondence: sadaqat.ali@univ-lorraine.fr (S.A.); zhixue.zheng@univ-lorraine.fr (Z.Z.); michel.aillerie@univ-lorraine.fr (M.A.)

\begin{abstract}
The fast depletion of fossil fuels and the growing awareness of the need for environmental protection have led us to the energy crisis. Positive development has been achieved since the last decade by the collective effort of scientists. In this regard, renewable energy sources (RES) are being deployed in the power system to meet the energy demand. The microgrid concept (AC, DC) is introduced, in which distributed energy resources (DERs), the energy storage system (ESS) and loads are interconnected. DC microgrids are appreciated due to their high efficiency and reliability performance. Despite its significant growth, the DC microgrid is still relatively novel in terms of grid architecture and control systems. In this context, an energy management system (EMS) is essential for the optimal use of DERs in secure, reliable, and intelligent ways. Therefore, this paper strives to shed light on DC microgrid architecture, control structure, and EMS. With an extensive literature survey on EMSs' role, different methods and strategies related to microgrid energy management are covered in this article. More attention is centered on the EMS for DC microgrids in terms of size and cost optimization. A very concise analysis of multiple optimization methods and techniques has been presented exclusively for residential applications.
\end{abstract}

Keywords: DC microgrid; energy management system (EMS); renewable energy sources (RES); distributed generators (DG); hybrid energy storage system (HESS); residential applications

\section{Introduction}

The global energy demand exponentially increases as the world population rises. In recent decades, an accelerated effort has been made for the development of renewable energy sources (RES). Many countries have taken the initiative to deploy renewable energy technologies on a large scale. The European Commission has set the following objectives for the promotion of RES inside the European Union (EU), to be achieved by 2030. The main goals are to achieve at least a $40 \%$ reduction in greenhouse gas emissions compared to 1990 levels, $32 \%$ of EU energy from renewables, and a 32.5\% improvement in energy efficiency [1].

Today, many countries have started to generate power through RES. According to Renewables 2021 Global Status Report, more than 256 GW of new renewable power generating capacity was installed worldwide in 2020, raising the global total to $2839 \mathrm{GW}$ by year's end [2], as shown in Figure 1.

The COVID-19 crisis has greatly harmed the global growth in renewable power capacity. Despite this, according to International Energy Agency (IEA), renewable power installations will increase worldwide in 2021 as compared to the previous year. The major 
reason is that most of the delayed projects which were not completed because of the unprecedented COVID-19 crisis are expected to come online [3].

The concept of a microgrid is introduced to overcome environmental depletion by harvesting distributed energy from RES, such as photovoltaic (PV) and wind energy, which are playing a major role in clean energy production. Microgrid technologies have demonstrated three principle beneficial properties, namely reliability (physical, cyber), sustainability (environmental considerations), and economic (cost optimizing, efficiency).

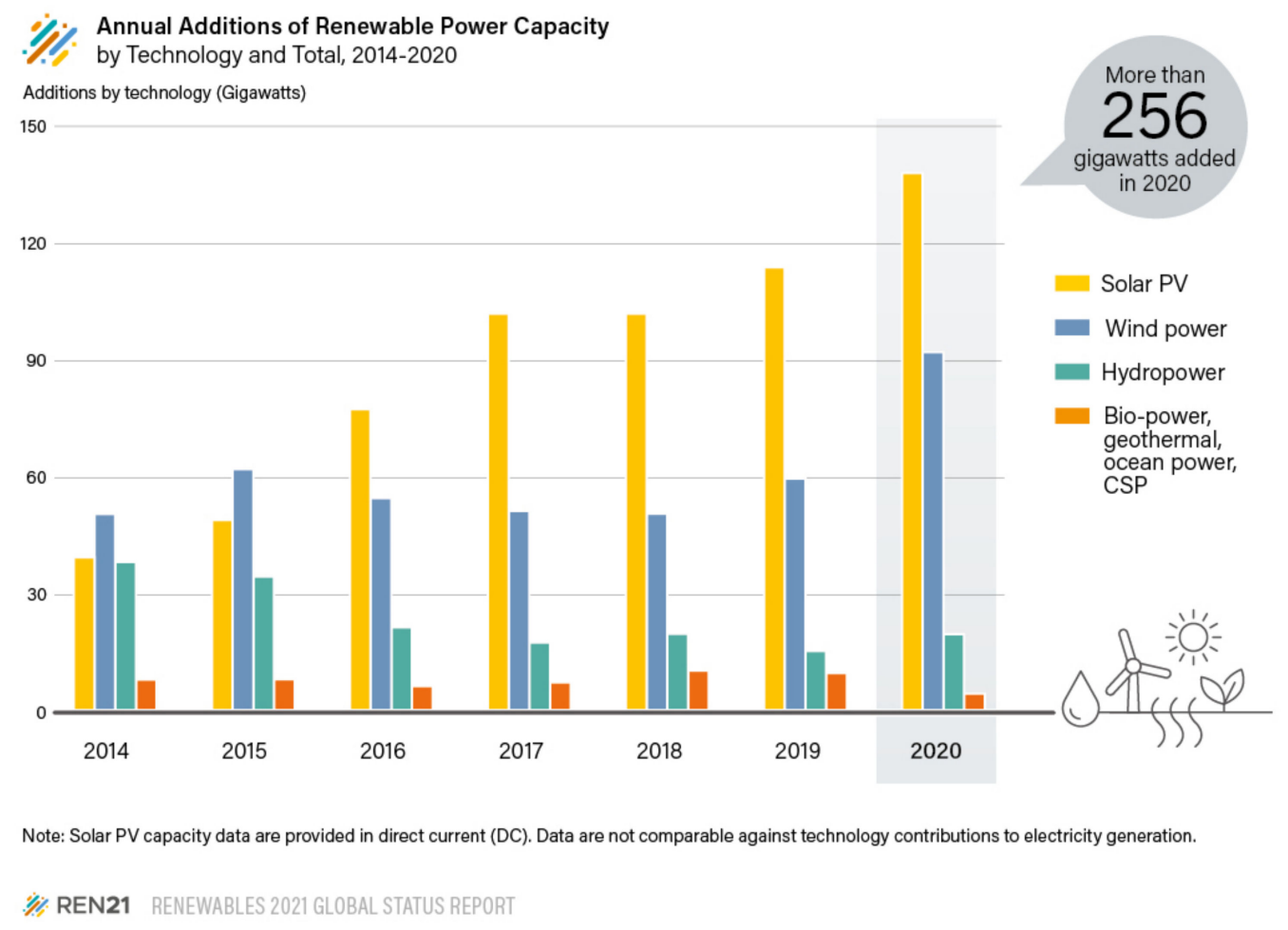

Figure 1. Annual additions of renewable power capacity by technology worldwide, 2014-2020 [2].

A microgrid is defined as a low-voltage distribution network, in which DERs are interconnected with the loads. As can be seen in Figure 2, various RES (e.g., PV panels, wind turbine), energy storage system and loads are connected to the main grid via power converters, with proper protection, communication, monitoring, and control systems. It can operate either in grid-connected mode or islanded mode subject to the operational characteristics of the main grid.

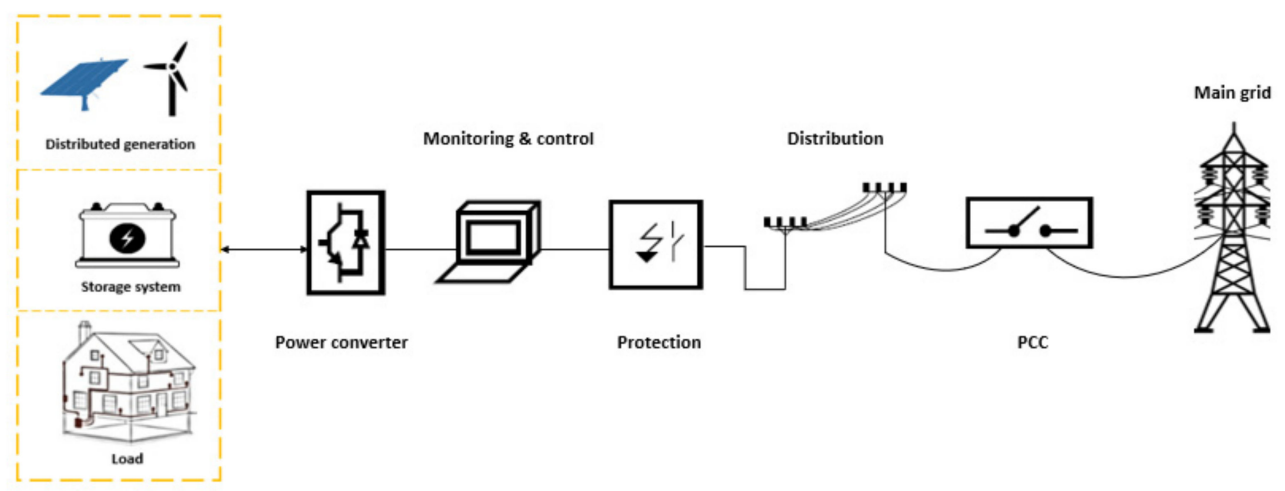

Figure 2. A typical microgrid architecture (adapted from [4]). 
Microgrids present both AC and DC distribution lines. Each type has their own transmission and distribution levels. Points of common coupling (PCC) constitute the gateway between the main grid and microgrid. The protection mechanisms guarantee an operation, which is designed by different principles and parameters according to the system. Parameters such as voltage, frequency and power quality are continuously supervised and controlled by means of proper monitoring systems and control strategies. Thus, power converters are the essential components of the grid system for AC/DC or DC/AC conversions. In distributed generation systems, two types of generation technology are applicable for microgrid, i.e., renewable distribution generation systems from RES (e.g., solar thermal, $\mathrm{PV}$, wind, fuel cell and biomass), and systems from non-renewable ones (e.g., diesel engine, stream turbine and gas engine) [5]. Among them, solar and wind technologies have rapidly increased and become significant energy sources in microgrids. Storage systems holds great importance for the stability, reliability, and the overall performance in a microgrid system. An overview of the different storage technologies, which can be separated into chemical, electrical, electrochemical mechanical and thermal systems, are discussed in [6]. Some key energy storage technologies used for microgrid applications are discussed in [7]. A microgrid system has various kinds of load (AC, DC). The load classification is important in terms of operating strategy for the overall microgrid management [8].

Considering the nature of the voltage and current, microgrids are sub-categorized into three types, i.e., AC, DC, and hybrid. Each alternative has distinctive features, which provide different advantages and disadvantages that need to be contemplated. Comparison between each type of microgrid in terms of control, protections and power losses was discussed in [4]. The AC microgrid has the benefit of using power from the main grid. The AC microgrid structure is based on AC bus and all sources (e.g., wind turbine) with variable frequency and different voltages connected to the bus through $\mathrm{AC} / \mathrm{AC}$ power converters. Sources with DC output (e.g., photovoltaic panels) are connected to the AC bus through DC/AC converters. However, an AC microgrid needs a relatively complex controller for importing and exporting power while maintaining the system stability and reliability. While in the DC microgrid structure, sources with DC output are directly connected to the bus, sources with AC output are interfaced to the DC bus through AC/DC converters. Thus, the DC microgrid has advantages over the AC microgrid in terms of system efficiency and size, which also result in an advantage considering the investment and operating cost. Indeed, in the DC system, a lesser number of power converters are required, making possible an optimization of the size and an improvement of the overall efficiency. Nevertheless, the protection system of DC distribution is not mature enough compared to the AC system. More research is needed on factors such as its protection system, architecture design, control strategies and stabilization techniques in future power systems [8]. A hybrid microgrid can supply both AC and DC loads due to its hybrid AC and DC buses.

In general, RES are integrated with energy storage devices to form a hybrid system to satisfy a given load demand. The PV and wind turbine (WT) combination provides more reliable power compared to individual systems. Wind and solar have a strong dependency on the environmental conditions, which is considered as a drawback of the system. Nevertheless, this problem can be solved by combining energy storage units as a backup. These additional elements usually increase the overall cost of the system. Therefore, optimal sizing and energy management systems are essential to decrease the system cost and attain system reliability.

Due to the increase of RES in microgrid systems, the significant role of EMSs has been observed in the literature. Researchers have concentrated on solving energy management problems to achieve a high level of operational efficiency while satisfying certain system constraints, to realize an economical, sustainable, and reliable operation of microgrids [9-12]. Different energy management strategies have been proposed in the literature to achieve an efficient and optimal operation of microgrids. Extensive research has been carried out by using search filters to find the literature related to certain subjects, including EMS, DC 
microgrid and residential application. The analysis of search filters was conducted in Web of Science, Google Scholar and Scopus. In total, 103 articles and 2 handbooks have been consulted. A total of 74 articles are related to the general EMS, among them 56 articles about microgrid EMSs which are published in high impact journals. The representative publications in previous years are further classified and analyzed in Section 3.

In Reference [13], authors proposed an EMS model based on a machine learning algorithm. The EMS here was formulated in such a way that real-time prosumer energy demand was calculated and fulfilled. Additionally, a novel graphic tool was proposed in this article to better represent, observe, and analyze microgrid energy flow. The paper [14] reviews the system components, modeling, and control of microgrids for smart buildings. Various data-driven forecasting methods for the building-integrated microgrids' control were discussed. In Reference [15], a comparative and critical analysis on decision-making strategies and their solution methods for microgrid EMSs was performed. The authors in Reference [16] presented a multi-agent system (MAS) for the stability, security, and reliability of microgrid systems. A comprehensive review on size optimization methodologies, and critical comparison of several algorithms is shown in Reference [17]. In this article, authors evaluated the possible combinations of standalone solar and wind energy systems. In Reference [18], centralized and decentralized EMSs of microgrids are discussed in detail. The author focused objectives such as power management, economic dispatch, and unit commitment. Several linear and nonlinear methods are covered in the article. The authors in References $[19,20]$ presented different optimization methods used for energy management and control of HRESs and ESSs. A comprehensive review on software tools and algorithms used for sizing objectives was also discussed. In Reference [21], authors discovered several linear programming and intelligent techniques for the energy management of stand-alone and grid connected HRESs. Optimal sizing, modeling, control aspects and reliability issues in microgrids were discussed by authors in Reference [22]. In Reference [23], authors presented an energy management plan for microgrids. It covered different computational optimization techniques applied to scheduling, reliability, environmental, and sizing problems.

Considering the electric vehicle as a storage element, the plug-in electric vehicle (EV) appears to be a crucial agent in the energy management of residential applications. The authors in Reference [24] discovered several energy management approaches, in which EVs are linked with microgrids as a major player. In Reference [25], authors presented a rule-based control strategy to manage the power flow between grids, batteries, and EVs. The benefits of using an electric vehicle as an active agent in energy balance and a reduction of cost are shown in the study.

Most literature reviews have mainly focused on the EMS issues of AC or hybrid microgrid systems. Different aspects of microgrids have been addressed, such as protection and control schemes, reactive power compensation and frequency control to solve energy management problems. Nevertheless, the EMS issues in DC microgrid systems have not been specifically and substantively addressed, especially for residential applications. Hence, this review paper contributes by providing a comprehensive review of various EMSs applied for DC microgrids in residential applications.

The paper is structured as follows. Section 2 presents the DC microgrid architecture, communication technologies and microgrid control structure. In Section 3, EMSs with different strategies in DC microgrids are classified and reviewed. Some existing EMS strategies for DC microgrid residential applications are also discussed in this section. Some relative discussions are made in Section 4. Finally, Section 5 draws conclusions.

\section{DC Microgrid Architecture}

\subsection{Physical Architecture}

In an architectural context, a DC microgrid comprises distributed generators (DGs), a storage system (SS), power converters and loads interconnected through one or more DC buses, as shown in Figure 3. Power converters (AC/DC, DC/AC) are still necessary 
because several sources and loads cannot be directly connected to the DC bus. During normal operating conditions, two types of microgrid network (AC, DC) are interconnected through PCC while the loads are supplied from the local sources (RES based DG units) and, if necessary, from the main grid. If the load demand power is less than the power produced by DG units, excess power can be exported to the main system which can be utilized in case of short production.

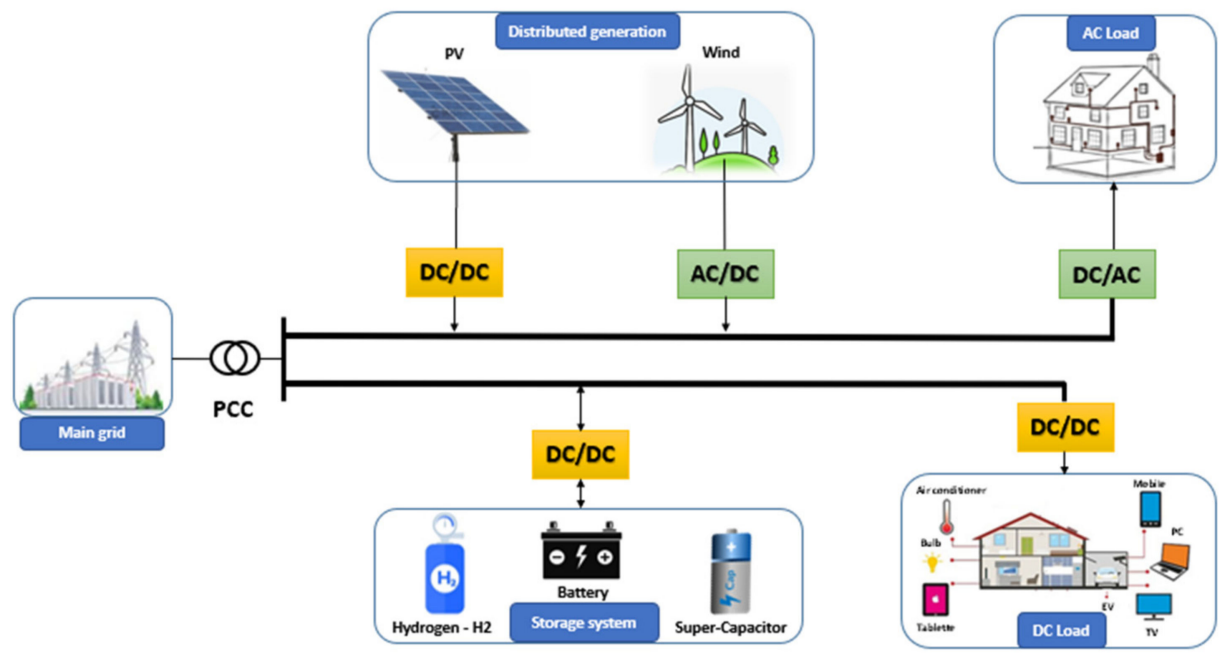

Figure 3. Illustration of DC microgrid scheme.

With the integration of these components, the whole system becomes simpler as compared to an AC microgrid. A smaller number of converters are required because most of the microgrid elements have DC nature, which reduces the system cost and gives higher efficiency in terms of losses. Due to the system's simplicity, reactive power and harmonic distortion is not a problem in such a kind of system. Despite all these advantages, the DC microgrid has some challenges at the same time, because the structure of the present power grids, transformers, cables, and even the protection system is designed specifically for AC applications. For this reason, the most feasible solution suggested by many researchers is to build a hybrid AC/DC microgrid system for a better integration of all elements with the main grid [26-28].

This idea presents a new paradigm for the definition of the distributed generation operation, in which AC and DC sources are connected to the corresponding networks. These networks are linked together through PCC with the main grid, as presented in Figure 3. Specifically, this paper attempts to show the DC microgrid system for residential applications. Therefore, it discusses the system design and control of microgrids in terms of different voltage levels and its application.

In residential DC microgrid systems, generally, distributed generators, energy storage system and local loads are connected through a common DC bus by means of line regulating converters, or are directly connected depending on the operating bus voltage. Several voltage levels have been found in the literature concerning residential DC microgrids varying from $5 \mathrm{~V}$ to $400 \mathrm{~V}$. These DC bus voltages are inspired by existing DC applications, such as universal serial bus (USB), which is the most common way to distribute $5 \mathrm{~V}$ of DC power. Transport applications such as camping cars operate with 12-24 V, and telecommunication applications operate with $48 \mathrm{~V}$ [29]. Concerning residential application operating on a $24 \mathrm{~V}$ DC bus, a design of a $250 \mathrm{~W}$ DC solar nano-grid with $24 \mathrm{~V}$ DC distribution bus was presented in [30]. In some literature, a small scale of DG such as a single house or a building is considered as a nano-grid but in this article, the microgrid term is used in a general sense. Another voltage level of 380-400 V was investigated in the literature used for the data centers. A $380 \mathrm{~V}$ DC test system was presented in [31], which has been constructed in Obihiro, Japan. It was concluded that the system allowed 
not only the reduction of the environmental load while improving energy efficiency but also the formation of an independent community energy system. In [32], the authors have implemented an experimental platform of DC microgrid with a bus voltage level of $380 \mathrm{~V}$. The system is composed of a PV array, a WT, an energy storage system by lithium battery pack and a supercapacitor, LED lights and controllable electric loads. It has been shown that the converter performances were well achieved. Moreover, the ability to control the power distribution between each unit connected to the bus was validated. The existing DC bus levels in residential applications in the literature, with their pluses and minuses, are summarized in Table 1.

Table 1. DC bus levels for residential applications [30-33].

\begin{tabular}{|c|c|c|}
\hline Voltage Level & $\begin{array}{c}\text { Application in Residential } \\
\text { Domain }\end{array}$ & $\begin{array}{c}\text { Remarks } \\
\text { (Advantages }+ \text {, Disadvantages }- \text { ) }\end{array}$ \\
\hline $5 \mathrm{~V}$ & $\begin{array}{l}\text { Universal serial bus (USB) } \\
\text { connections. } \\
\text { Small rechargeable batteries. }\end{array}$ & $\begin{array}{c}\text { + Easy to connect with a device and } \\
\text { distribute power. } \\
\text { - Short application range. }\end{array}$ \\
\hline $12 \mathrm{~V}$ & $\begin{array}{l}\text { Low load applications for } \\
\text { short distance. }\end{array}$ & $\begin{array}{l}\text { + Safe and same level of DC } \\
\text { appliances. } \\
\text { - Designed for low power } \\
\text { usage. }\end{array}$ \\
\hline $24 \mathrm{~V}$ & $\begin{array}{l}\text { High power applications for } \\
\text { long distance }\end{array}$ & $\begin{array}{l}\text { + Low level power distribution } \\
\text { according to the standard. }\end{array}$ \\
\hline $48 \mathrm{~V}$ & $\begin{array}{c}\text { New automobiles charging } \\
\text { infrastructure. } \\
\text { Telecommunication } \\
\text { instruments such as wireless } \\
\text { phones, ethernet. }\end{array}$ & $\begin{array}{c}\text { + Within the standard of IEEE for } \\
\text { DC microgrid. } \\
\text { Simple protection. }\end{array}$ \\
\hline $380-400 \mathrm{~V}$ & $\begin{array}{c}\text { For DC computer data centers } \\
\text { and possibly commercial } \\
\text { buildings as a residential } \\
\text { application. }\end{array}$ & $\begin{array}{l}\text { + Within the standard of Emerge } \\
\text { Alliance of buildings. } \\
\text { Easily compatible with main grid. } \\
\text { More appropriate for DC } \\
\text { microgrid residential applications. } \\
\text { - Additional converter required. } \\
\text { Protection is compulsory. }\end{array}$ \\
\hline
\end{tabular}

As can be seen, most DC appliances generally operate on $12 \mathrm{~V}$ or $24 \mathrm{~V}$. However, with the development of standards such as IEEE 2030.10-standard for DC microgrids [32], DC loads running on $48 \mathrm{~V}$ now also exist in the market. Therefore, for the time being, most of commercialized DC home appliances operating on $5 \mathrm{~V}, 12 \mathrm{~V}, 24 \mathrm{~V}, 48 \mathrm{~V}$ are presented in Table 2, with their power ranges and operating voltages.

The specific power range of appliances may negotiate different voltage capabilities for the access of electricity. Depending on the power of appliances (low power, medium power, and high-power appliances), different voltage levels ( $5 \mathrm{~V}, 12 \mathrm{~V}, 24 \mathrm{~V}, 48 \mathrm{~V})$ could be defined. Based on the literature survey, this work considers 380-400 V voltage level for the proposed DC system environment. With this voltage level, additional converters are required for adapting available appliances, and it is easily compatible with utility voltage $230 \mathrm{~V}$ AC with a minor modification. Therefore, for residential applications, a 380-400 V DC bus could be an appropriate voltage level. Additionally, proper control and protection is necessary for the system reliability and stability. 
Table 2. Typical DC load household appliances [33-35].

\begin{tabular}{|c|c|c|c|c|c|}
\hline \multirow[t]{2}{*}{ Appliance } & \multirow[t]{2}{*}{$\begin{array}{c}\text { Power Range } \\
\text { (W) }\end{array}$} & \multicolumn{4}{|c|}{ Rated Voltage (V) } \\
\hline & & 5 & 12 & 24 & 48 \\
\hline USB Port & 2.5 & $\Delta$ & & & \\
\hline Led lamp & $3-40$ & & $\Delta$ & $\Delta$ & $\Delta$ \\
\hline Fan & $3-36$ & & $\Delta$ & $\Delta$ & $\boldsymbol{\Delta}$ \\
\hline Air conditioner & $444-816$ & & & $\Delta$ & \\
\hline Refrigerator & $40-150$ & & $\Delta$ & $\Delta$ & $\Delta$ \\
\hline Microwave & $660-1100$ & & $\Delta$ & & \\
\hline Coffee maker & $900-1200$ & & $\Delta$ & $\Delta$ & \\
\hline Computer & $21-80$ & & $\Delta$ & $\Delta$ & \\
\hline Television & $65-120$ & & $\Delta$ & $\Delta$ & $\Delta$ \\
\hline Washing machine & $70-360$ & & $\Delta$ & $\Delta$ & \\
\hline Iron & $130-150$ & & $\Delta$ & & \\
\hline
\end{tabular}

\subsection{Communication Technologies}

In microgrid systems, an efficient data communication system is required for continuous, fast, and reliable operation. Selection of a microgrid communication system depends on system configurations and its protocols. Control objectives, its implementation and cost are also important factors to consider.

In the literature, several wired and wireless communication technologies have been suggested for effective communication among different microgrid components. It depends on the data rate, distance, quality of service, reliability, and power consumption. Commonly wired technologies such as ethernet, power line communication (PLC), and fiber optics have a higher data transmission rate and reliability, but the installation cost is relatively high. Meanwhile, technologies such as ZigBee, Z-wave, global system for mobile communications (GSM), general packet radio service (GPRS) and worldwide interoperability for microwave access (WiMAX or Wi-Fi) can be deployed with lower installation cost. Both wired and wireless communications are studied in this article. Wired networks are preferred because of reliability and security reasons, while wireless technologies are more advantageous in terms of low deployment cost. However, they have a low data transmission rate and signal interference problems [15]. An overview of different communication technologies that can be used for microgrid operations is summarized and compared in Table 3.

In the literature, several internet protocols (IP) have also been discussed, which provide internet services in microgrid applications. The most used protocols are network timing protocol (NTP) for time synchronization, transmission control protocol (TCP) and user datagram protocol (UDP). In Reference [39], a Modbus protocol was used for data exchange between programmable logic controllers (PLCs). Two main versions of Modbus were presented in this study, i.e., remote terminal unit (RTU) and TCP, known as Modbus TCP/IP. It basically consists of the Modbus RTU protocol with a TCP interface that runs on ethernet and is widely used for industrial networking and communication.

The most used standards in wired communication for serial transmission are RS-232, RS-422 and RS-485, which could be deployed over various physical links such as fiber optics and ethernet for microgrid networking. RS-485 protocol is mostly used for the energy management of DC microgrid systems. Another open standard, which is widely used for commercial and domestic building automation, is called Konnex. In Reference [40], authors used it with international standard Modbus for the energy management of smart buildings. 
Table 3. Grid communication technologies' parameters [36-38].

\begin{tabular}{|c|c|c|c|}
\hline Technology & Data Rate & Coverage Range & Applications \\
\hline \multicolumn{4}{|l|}{ Wired } \\
\hline Broadband PLC & Up to $300 \mathrm{Mbps}$ & Up to $1500 \mathrm{~m}$ & Smart grid, HAN \\
\hline Narrowband PLC & $\begin{array}{c}10-500 \\
\text { Kbps }\end{array}$ & Up to $3 \mathrm{~km}$ & Smart grid, HAN \\
\hline Ethernet & Up to $100 \mathrm{Gbps}$ & $\mathrm{Up}$ to $100 \mathrm{~m}$ & $\begin{array}{l}\text { SCADA, backbone } \\
\text { Communication }\end{array}$ \\
\hline Fiber optics & Up to $100 \mathrm{Gbps}$ & Up to $100 \mathrm{~km}$ & SCADA, HAN \\
\hline \multicolumn{4}{|l|}{ Wireless } \\
\hline GSM & Up to $14.4 \mathrm{kbps}$ & $1-10 \mathrm{~km}$ & $\begin{array}{l}\text { AMI, HAN, BAN, } \\
\text { IAN }\end{array}$ \\
\hline GPRS & $\begin{array}{l}\text { Up to } 170 \\
\text { Kbps }\end{array}$ & $1-10 \mathrm{~km}$ & $\begin{array}{l}\text { AMI, HAN, BAN, } \\
\text { IAN }\end{array}$ \\
\hline WiMAX & $\begin{array}{l}\text { Up to } 75 \\
\text { Mbps }\end{array}$ & $\mathrm{Up}$ to $50 \mathrm{~km}$ & $\begin{array}{l}\text { AMI, Mobile } \\
\text { workforce } \\
\text { management }\end{array}$ \\
\hline Z-wave & $\begin{array}{l}40-250 \\
\text { Kbps }\end{array}$ & $\begin{array}{l}30 \mathrm{~m} \text { point-point, } \\
\text { Unlimited with mesh }\end{array}$ & $\begin{array}{l}\text { AMI, HAN, BAN, } \\
\text { IAN }\end{array}$ \\
\hline ZigBee & $250 \mathrm{kbps}$ & $100+$ meters & AMI, HAN \\
\hline
\end{tabular}

\subsection{Control Structure}

In regard to microgrid reliability, stability and proper operation, the control structure has great importance. Many researchers have addressed the operational and control issues in microgrids to allow their stable operation in both grid-connected and islanded modes. The microgrid control structure is based on various objectives. For example, based on their controller function, connection with grid and response time, a systematic classification of various control techniques is presented in Figure 4.

With reference to power systems control architecture, control techniques can be categorized into centralized, decentralized, and distributed control, as shown in Figure 5. In centralized control, the microgrid central controller (MGCC) controls the actions of all units. In this control, substantial communication is required between all units and the central controller. Due to large geographical area and distance, it is not feasible to have a fully centralized control among microgrids. In decentralized control, every single unit is controlled by its own local controller, and it receives only local information such as frequency and voltage. Some local controllers can exchange information with the neighbor control unit. However, with little communication, fully decentralized control is also not possible because of the dependency of various units within the system. It can cause the system to become unstable or operate non-optimally. Therefore, a compromise between these two controls can be obtained by introducing a third approach called the distributed control scheme. It consists of some degree of centralizing along with some degree of decentralized properties. In the distributed control method, each unit uses local information such as frequency and voltage provided by its neighbors. In this method, local units exchange information through two-way communication links. This method can also preserve the unit's privacy because a lot of important information is not shared globally [41]. 


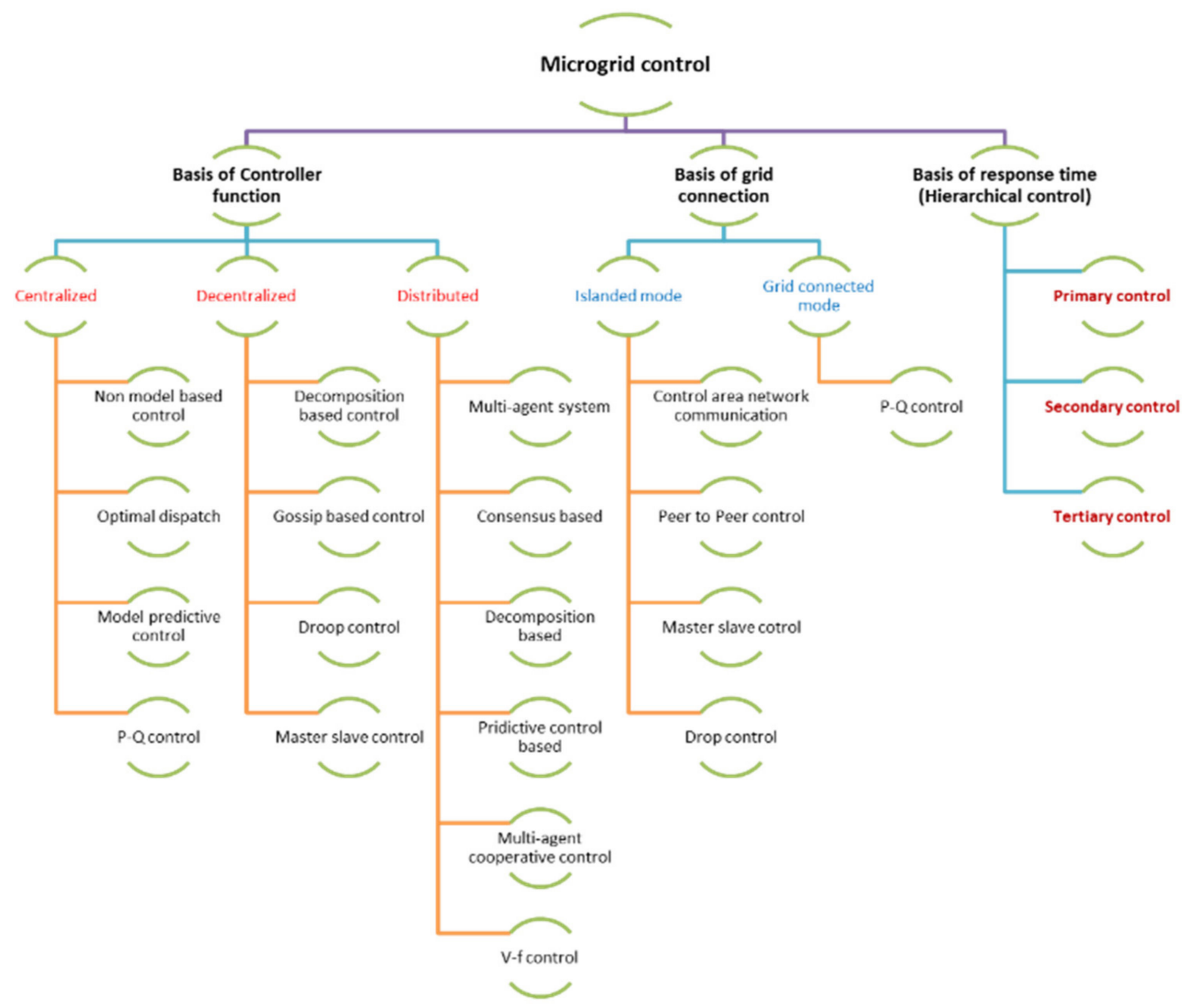

Figure 4. Classification of various microgrid control techniques (summarized based on [42-44]).

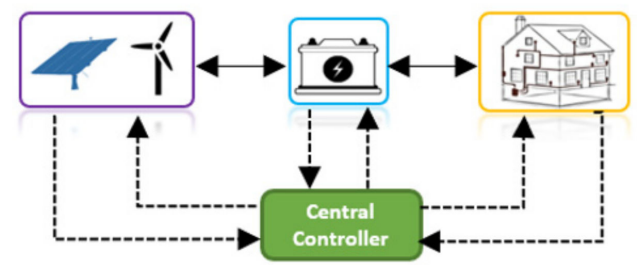

Centralized control

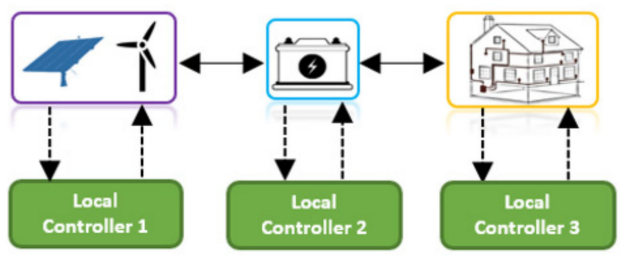

Decentralized control

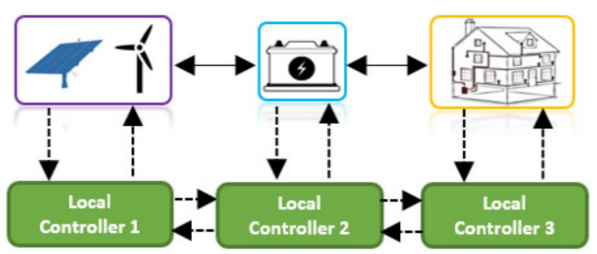

Distributed control

Figure 5. Illustration of centralized, decentralized, and distributed control schemes (adapted from [42]). 
It is important to note here that PV, WTs, and storage systems with the loads in Figure 5 are used as an illustration in a nano-grid scale. Each unit can be further replaced by one or several nano-grids to constitute a larger scale microgrid.

Control Objectives and Scope

The main building block of a microgrid integrates several DG units, energy storage systems and loads together to build a small power system. To control such systems, it is important to define a set of controlling objectives. By doing this, the proper operation of the system is achievable. The hierarchical control structure has been proposed in the literature $[45,46]$ which consists of three levels, i.e., primary, secondary, and tertiary control, as shown in Figure 6.

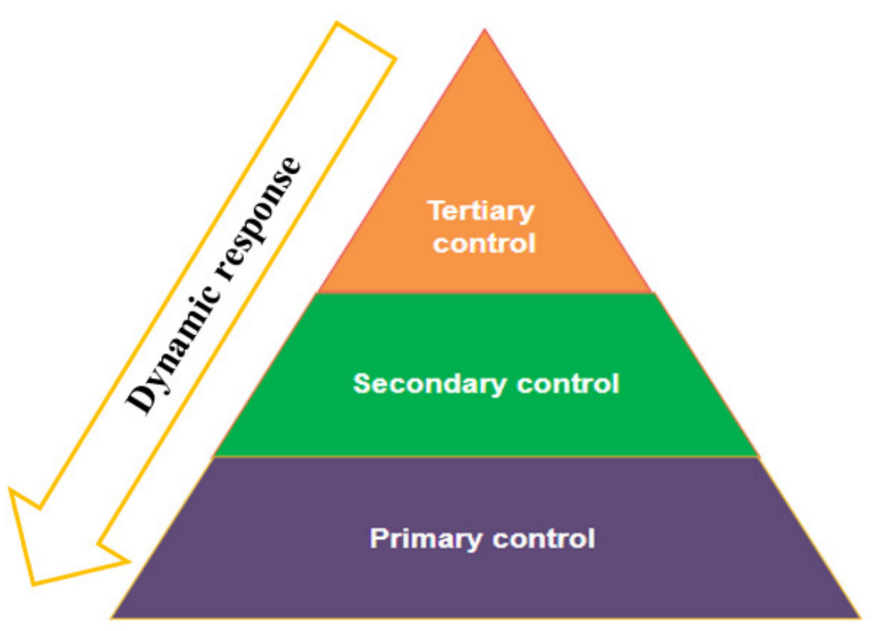

Figure 6. Hierarchical control levels in a microgrid structure (adapted from [46]).

The primary control is based on each local DG controller, which mainly involves voltage loop control, current loop control, MPPT control and SOC estimation. As there is no information exchange between each DG, they are totally decentralized. Secondary control is a higher level than primary control. It is linked with the voltage compensation and sharing performance enhancement. It deals with voltage control for the regulation of DC bus voltage. The tertiary control is on the top layer of the microgrid control diagram, and its dynamic response is the slowest one among the three layers. In the tertiary control, economic dispatch, power flow optimization, and optimal energy scheduling issues are usually considered. In Reference [45], the tertiary control is regarded as EMS, which is designed to achieve the accurate power sharing control among DG units, and the power exchange between microgrid and external grid in the case of grid-connected mode. Additionally, it deals with the energy market, organizing the energy dispatch scheduling from an economic point of view. Based on the hierarchical control, energy management strategies can be defined. Hence, the decisions on microgrids are made by the EMS. In this sense, multi-objective functions ought to be specified by using information such as demand forecasting, power generation, energy storage, weather forecasts, energy grid prices, and so on [47-49]. Based on the previous literature review [18,20,50,51], analysis has been conducted based on multi-objective functions. The research objectives and scopes are detailed as follows:

1. The primary control is implemented on each local DG according to a decentralized control scheme. The objective is essentially to regulate the local voltages and currents. It also controls the breakers/switches (on/off and protection functions) and load control (curtailment functions).

2. Primary control may cause voltage deviations, especially when the heavy loads are connected to or disconnected from the microgrid. The system might run abnormally 
or drop into under or over voltage protection. The objective herein is to develop a distributed secondary control scheme for voltage quality enhancement, such as voltage unbalance compensation. For regulating the DC bus voltage, droop control is recommended for the voltage control among microgrids. The proposed control scheme should be flexible and make the controller have the plug-and-play property.

3. A tertiary control structure is developed in a way that the microgrid central controller considers the optimal power flow, economic dispatch, and optimal energy scheduling problems in the microgrid to formulate an EMS. The EMS uses inputs (weather forecast, load demand, SOC, energy prices, etc.) to carry out scheduling and optimization procedures. It determines the optimal set points for distributed generation (DG) and load operation in the microgrid.

Based on the objective functions, a typical hierarchical control for a DC microgrid is summarized and presented in Figure 7. In this way, the control system can be more flexible and reliable while respecting the system objectives and the operating constraints.

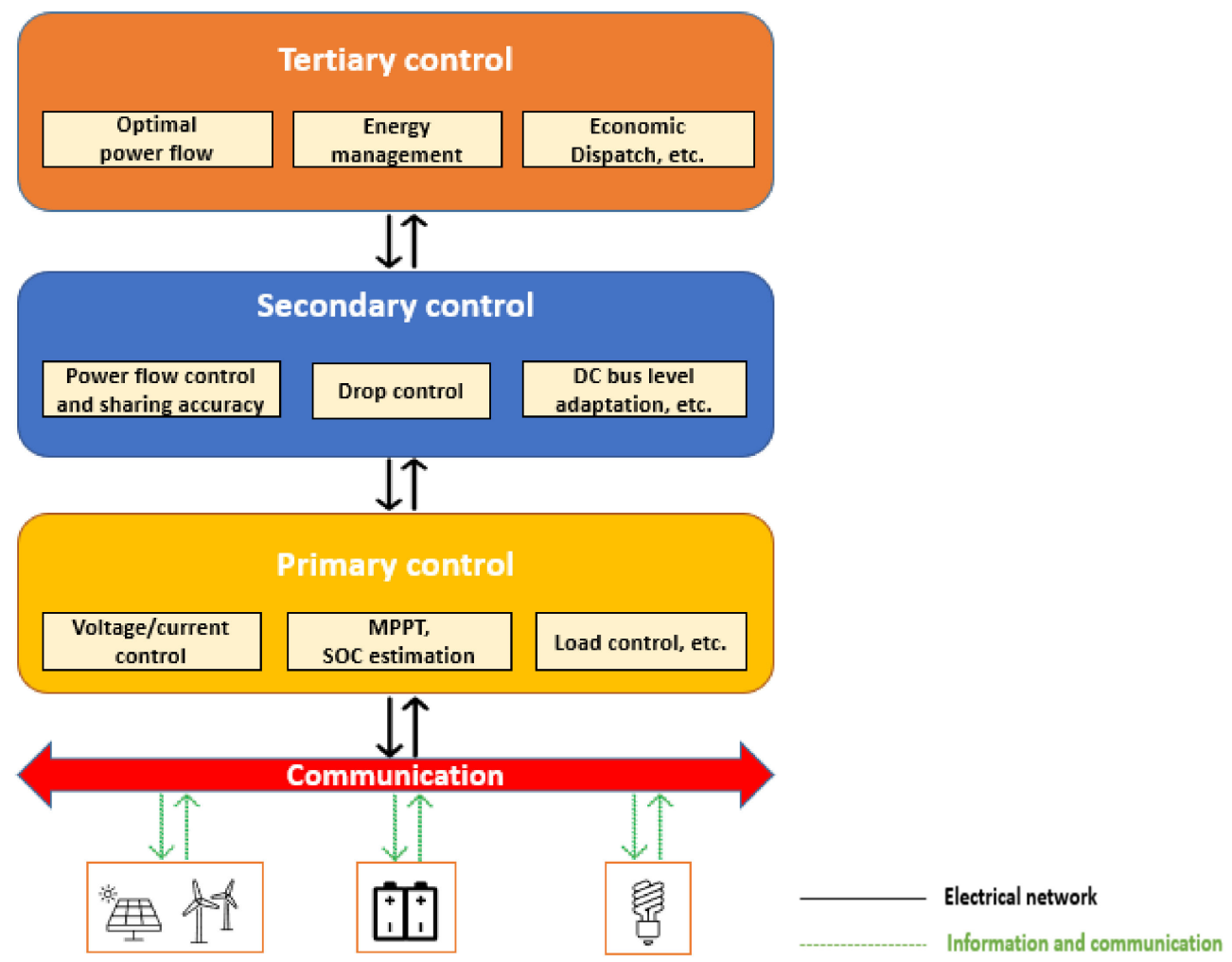

Figure 7. Typical control objectives and functions in a DC microgrid.

\section{DC Microgrid Energy Management System (EMS)}

The microgrid EMS is a multi-objective system that deals with technical, economical, and environmental issues. The main objectives of the EMS are to optimize the operation, energy scheduling, and system reliability in both grid-connected and islanded modes. Therefore, for control purposes, it is necessary within a microgrid that an EMS has a connection with each part of the system, as shown in Figure 8. The whole microgrid operation is controlled and coordinated by a microgrid central controller (MGCC) and local controllers (LCs) via a communication network called information and communication technology (ICT) [52]. It should be noted that as a single microgrid is illustrated herein (with less geographical area and distance), a MGCC is applied for illustration. 


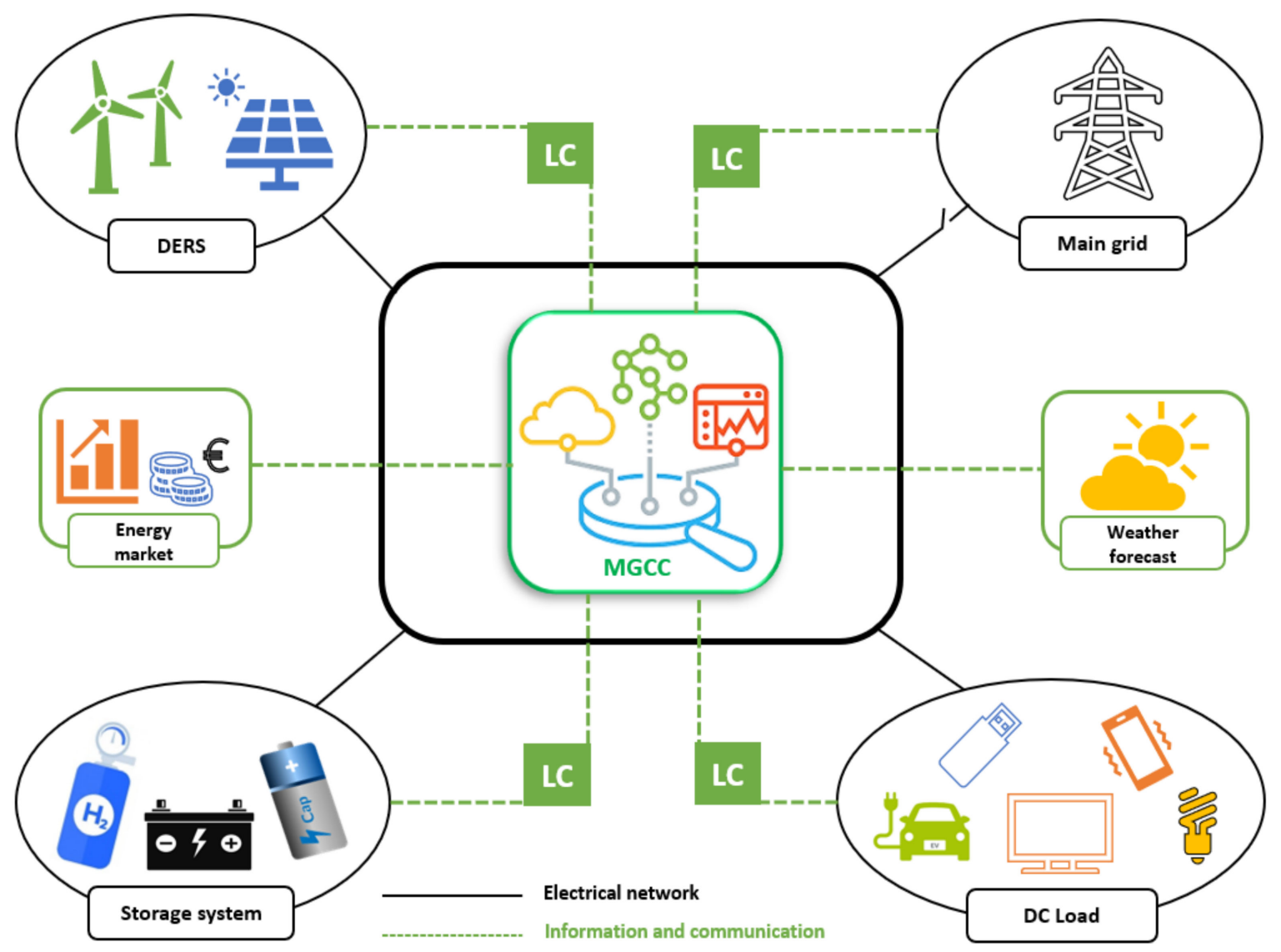

Figure 8. EMS-based DC microgrid architecture (adapted from [15]).

Different energy management strategies have been proposed in the literature to achieve an optimal and efficient operation of microgrids. Common techniques and methods used for the energy management of microgrid systems can be classified into two major categories, i.e., classical methods and artificial intelligence methods, as shown in Figure 9. In addition, several existing software tools and hardware components dedicated to residential applications are also listed at the end of this section. More details of each category are given in Sections 3.1 and 3.2. It should be noted that different classifications may exist in the literature, such as rule-based and optimization-based EMS. In addition, a practical EMS may be a combined form of different methods.

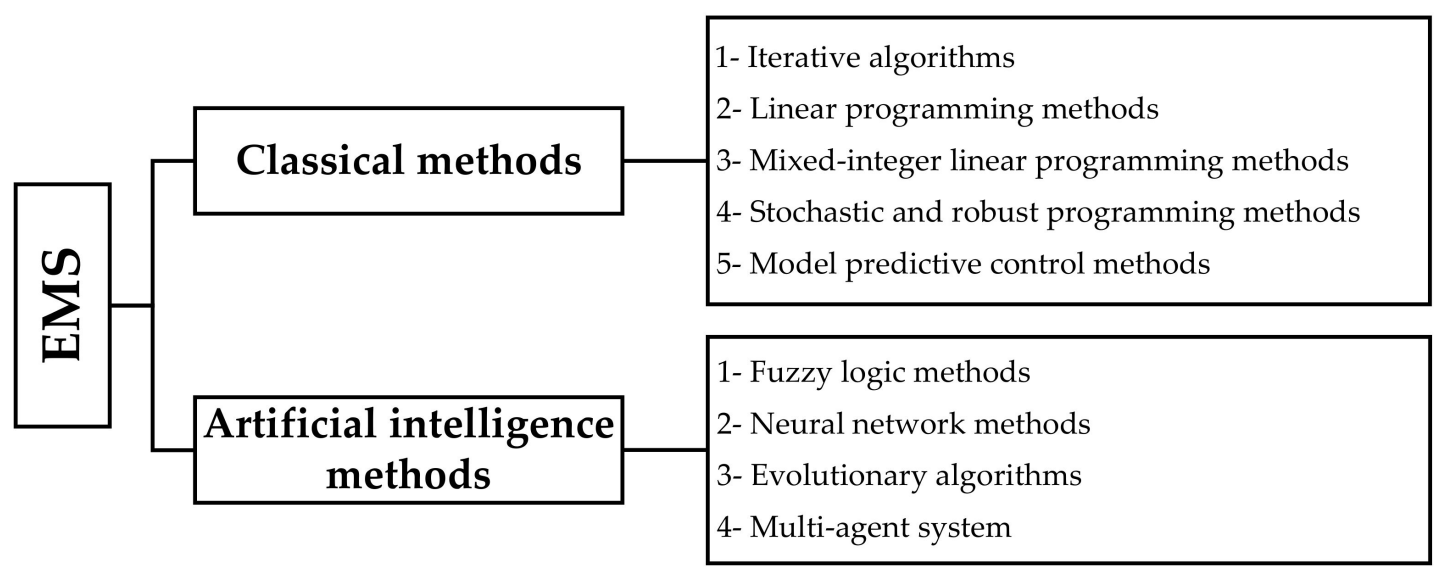

Figure 9. Proposed classifications of energy management strategies. 


\subsection{Energy Management Based on Classical Methods}

A limited number of studies have been carried out using classical methods for the energy management of a DC microgrid system. Most of the research has been conducted in the size optimization of standalone PV-WT HES [53-57]. However, they may provide useful guides for EMS design for residential applications. Commonly used classical methods include iterative, linear programming (LP), mixed integer linear programming (MILP), stochastic and robust programming methods, and model predictive control, which are reviewed in the following subsections.

\subsubsection{Iterative Algorithms}

In the literature, iterative algorithms are utilized to realize different objective functions. It has been implemented for the sizing optimization of standalone systems with single objective optimization (SOO) functions. In Reference [58], Hosseinalizadeh et al. applied an iterative algorithm to optimize a standalone PV-WT-FC-BS-HT HES in terms of minimizing the system's total cost of energy for four different regions in Iran. The authors of [56] evaluated the reliability of the HES by using loss of energy expectation (LOEE) and loss of load expectation (LOLE) as estimation parameters. In this study, it was assumed that the value of LOLE parameter must be less than $2 \%$ to achieve system reliability. The study found that the PV-WT-BS HES was more economical and reliable without the FC system. Bhuiyan et al. [59] proposed an enumeration-based iterative algorithm to perform energy management in terms of component size optimization within microgrid residential communities. This system comprised PV, WTs, a BS and DGs. In this research, the system reliability was evaluated by analyzing the battery SOC and the power balance between generation and demand. Furthermore, the study found the PV-WT-DG HES system to be techno-economic in meeting the energy demand of remote consumers.

\subsubsection{Linear Programming Methods}

A few studies have recently used linear programming (LP) to implement energy management in terms of optimizing the standalone HES with PV and WTs $[60,61]$. Nogueira et al. [60] suggested a methodology that uses LP to size and simulate a standalone PV-WTBS HES for a remote rural area by minimizing the total cost of the system while assuring the system reliability by using the measure of loss of power supply probability. Indu Rani et al. [62] proposed a residential microgrid system in which PV panels were connected to the grid to supply DC loads without any interruption. An effective power flow management system was designed to achieve this goal. Its effectiveness in providing uninterruptible power to DC loads and maintaining the total harmonic distortion (THD) of the injected grid current was proved. In Reference [63], Battistelli et al. suggested a practical prototype to assess the contribution of vehicle-to-grid (V2G) systems to supporting the electricity market. An optimization model based on a linear programming algorithm was integrated into the EMS to assess the interaction between the small electric energy systems (e.g., microgrids) and the main grid. Meanwhile, stochastic programming and robust optimization (more details in Section 3.1.4) were applied to deal with uncertainties related to renewable power generation and vehicle aggregation separately. Karami et al. [64] proposed a simple and efficient EMS for a hybrid system comprising a PV panel, a FC system, a battery, and a super-capacitor. Sixteen different scenarios covering both night and daylight were considered for the power flow management. The optimal energy production was achieved by the application of MPPTs on both PV and FC and the use of compensators. Pascual et al. [12] proposed an EMS for a residential microgrid system consisting of PV panels, a $\mathrm{WT}$, and a battery connected to the main grid. The main objective was to minimize the power peaks and fluctuations for energy exchange with the grid. The renewable generation and load forecasting together with the battery SOC were considered in a single control rule to achieve the goal. 


\subsubsection{Mixed-Integer Linear Programming (MILP)}

MILP is used for the modeling of energy management problems because it considers integer and binary variables to decide the operation system. In the literature, several authors used MILP methods for microgrid EMS according to the variables and objective functions. In Reference [65], Sukumar et al. proposed a power sharing, continuous run, and on/off-based mix-mode microgrid EMS. The on/off mode was modeled and solved by a MILP solution approach that optimizes the operation of the microgrid with respect to on/off connection status of the FC system. Meanwhile, the other two modes were modeled and solved by an LP method. Comodi et al. [66] introduced a MILP energy trade profit model-based EMS for a residential microgrid system. The PV power was forecasted by a basic neural network (NN) method. The integration of thermal storage and batteries was realized by load management. The batteries were concluded uncompetitive for the residential applications because of their high investment and replacement cost in the residential market. For optimal energy management of residential microgrid systems, an operating cost-minimization model based on MILP was proposed in [9]. It encompassed energy trading cost and penalty cost on adjustable load shedding. Both energy costs and battery wear costs were included in the minimization. In this study, three types of loads were considered, namely: critical, adjustable, and shiftable loads. The loads were divided into different power levels which analyzed the tradeoff between load demand and the battery state of charge (SOC).

\subsubsection{Stochastic and Robust Programming Methods}

Stochastic and robust programming is considered as a two-stage approach which deals with constrained optimization with uncertainty. In microgrid systems, energy management is facing new challenges due to the increasing number of variable generation sources. To meet these challenges, stochastic and robust optimization methods are proposed to overcome the uncertainties in Reference [67]. A probabilistic scenario-based optimal day-ahead economic operation was presented for a hybrid AC/DC microgrid system. It minimized the overall operating cost by using the forecasting values of electricity price, solar power, wind power, AC and DC loads. A two-stage stochastic programming model was presented in Reference [68] to optimize microgrid operation while considering uncertainties of RERs and load demand. The first stage was associated with optimization of investment cost of microgrid, and the second stage dealt with the energy management operation of the microgrid.

\subsubsection{Model Predictive Control Methods}

Model predictive control (MPC) is very useful for defining the energy management strategy in microgrid systems. In the literature, MPC is widely used to minimize the daily generation cost and emission of the microgrid system while considering the technical constraints in real operations. In Reference [69], Solanki et al. presented an EMS strategy based on a MPC approach. Authors put emphasis on the use of smart loads to perform an efficient operation. A supervised $\mathrm{NN}$ was used to estimate the residential controllable load. In another study [70], an MPC-based EMS of a grid-connected microgrid was presented to minimize the energy trading cost with the main grid, and to ensure a better utilization of the battery during peak load demand. It also ensured the maximum use of wind power to meet the local demand. Authors introduced a fault tolerant scheme to have a smooth operation of the microgrid during sudden failures of WTs and power supply shortage. Akter et al. [71] suggested a hierarchical model for power sharing among residential consumers. Each house was equipped with a central EMS controller to share information in a grid-connected mode residential microgrid. The intention was to maximize the energy sharing among houses in comparison with the main grid to minimize the investment cost. The authors concluded that the payback period was reduced due to power sharing among residential consumers. 


\subsection{Energy Management Based on Artificial Intelligence Methods}

Diverse studies have been focused on the utilization of artificial intelligence methods for the multi-objective energy management of microgrids. In this category, artificial intelligence techniques are used to solve single-objective optimization $(\mathrm{SOO})$ and multi-objective optimization (MOO) problems. In general, artificial intelligence methods are more flexible and efficient in dealing with complex optimization problems, such as fuzzy logic (FL), neural network (NN) and evolutionary computation methods. In addition, a multi-agent system (MAS) composed of multiple interacting intelligent agents has also been introduced to microgrids. This subsection gives a more detailed review of these studies.

\subsubsection{Fuzzy Logic Methods}

FL techniques are widely used for energy management in standalone or grid-connected hybrid renewable energy systems. FL can effectively manage the multi-control functions. Several studies have been found in the literature discussing FL-based EMSs. The design and implementation of an EMS based on fuzzy control for a DC microgrid system was presented in Reference [72]. In this work, the modeling, analysis, and control of the DERs and ES devices were completed in a MATLAB/Simulink environment. The FL controller managed the battery SOC to ensure a longer battery life and to offer better performance for the entire system at low cost. Different membership functions with variables were defined for both inputs and outputs of the system. The simulation result validated the accuracy of the proposed system with a fuzzy controller that can maintain the battery SOC at a certain level, irrespective of the amount of power generated from the microgrid system. Erdinc et al. [73] studied a FL-based EMS for a standalone hybrid power system. This residential system comprised WTs, PV, a FC system, and batteries. The PV and wind energy served as the primary power sources, the FC provided backup power during the unavailability of the primary sources, and the battery unit was used for storage. The main objective of this study was to employ an FL-based EMS to regulate the overall system power flow while maintaining the battery SOC. The authors herein justified the advantages of the FL-based EMS over other previously developed approaches, in the aspects of fast response capability and ease of adapting to new conditions during the period of operation.

\subsubsection{Neural Network Methods}

The neural network (NN) is another intelligent technique commonly used for control and energy management of microgrid systems. It is an advanced approach which is computationally intelligent and has human-like expertise. NN has achieved remarkable success in control system applications due to its reliability, computational capability, and adoptability to handle complex nonlinear systems. Wang et al. [74] introduced a Lagrange programming NN approach to optimize economic dispatch and minimize the system objective function. Meanwhile, a radial basis function NN was applied for the day-ahead prediction of renewable energy production and load demand. In Reference [75], Venayagamoorthy et al. proposed an intelligent adaptive dynamic EMS for a grid-connected microgrid. An action-dependent heuristic dynamic programming (ADHDP) combining the concept of dynamic programming and reinforcement learning was developed by using two NNs. Meanwhile, an evolutionary strategy was proposed to dynamically optimize the EMS over time. It maximized the utilization of RERs and minimized carbon emissions to achieve a reliable and self-sustainable system. It can also improve the battery life. Azmy and Erlich [76] presented an artificial NN approach for optimizing the performance of a FC system for residential applications. Jifang et al. [77] proposed a NN-based control strategy for a multi-energy common DC bus hybrid power system. The authors developed a hybrid model for an hourly forecast of a PV and wind renewable energy system.

\subsubsection{Evolutionary Computation}

Evolutionary computation is inspired by biological evolution and forms another popular subfield of artificial intelligence. Genetic algorithm (GA) is a random-based classical 
evolutionary algorithm. It is one of the most powerful optimization algorithms. In several studies [78,79], GA has been implemented to find the optimal sizing of a hybrid system. Ogunjuyigbe et al. [73] used GA for the optimal sizing of a hybrid energy storage system (HESs) in standalone mode. In this study, the authors inspected five different combinations for residential loads. The study found that PV-WT with HESs is the most optimal combination in terms of cost, net dump energy and $\mathrm{CO}_{2}$ emissions. In Reference [79], the authors used GA for the optimal sizing of renewable energy sources (RES) with a battery storage system (BSs) for four different residential zones in Karnataka, India. The study found that PV, WT, and BSs are the most cost-effective solution for residential applications. An improved version of GA, called non-dominated sorting genetic algorithm (NSGA-II), was discussed in [80,81]. Kamjoo et al. [80] applied the NSGA-II algorithm to optimize a standalone PV-WT-BSs combination for residential loads in Kent, UK and provided promising results in solving MOO problems.

Meanwhile, several other algorithms are also used to solve the non-linear optimization problem including particle swarm optimization (PSO), ant colony optimization (ACO), fruit fly optimization algorithm (FOA) and others. PSO is one of the most popular heuristic algorithms in solving the non-linear optimization problem because of its simplicity, ease of implementation and fast convergence. Suhane et al. [82] used ACO to find the optimal sizing of PV, WT, BS, and DG in terms of minimizing the total cost for a small village in India. Fruit fly optimization algorithm (FOA) is a heuristic evolutionary computation method used in finding global optimization. In Reference [83], authors utilized an improved FOA (IFOA) algorithm for the optimization design of a standalone PV-WT-BS-DG system on Dongao island in China. The study found that with a smaller number of WTs and battery units, total cost can be reduced.

\subsubsection{Multi-Agent System (MAS)}

A multi-agent system (MAS) is made up of intelligent agents embedded in different sources and loads working all together to solve the problem of energy consumption control in the network. A MAS-based approach is used for optimal operation of a microgrid system. All the system elements, such as storage units, generation units, grid and consumer side, are considered as an agent. Anvari-Moghaddam et al. [84] suggested a MAS-based EMS for efficient operation of a grid-connected residential microgrid. The agents were classified into central coordinator agent, building management agent, RER agent, battery agent, and service agent. The objectives of the proposed method were to minimize operational cost while satisfying the consumer's comfort level.

\subsection{Existing Software Tools and Sardware Components for Microgrid EMS}

This section introduces both software tools and hardware components used for microgrid applications. In the literature, many open-source software tools have been used for the optimization of hybrid renewable energy systems. The most used software tool in size optimization for PV-WT HES is Hybrid Optimization Model for Electric Renewables (HOMER) [85]. Another software, named Improved Hybrid Optimization by Genetic Algorithm (i-HOGA), has been used in several studies for sizing optimization for standalone PV-WT HES [86]. TRNSYS and graphical user interface (GUI) are graphically based software tools and are extremely flexible [87]. Several hardware components, such as Arduino, Raspberry Pi (RPi), and Color Control GX (CCGX), and SCADA, are explored in $[39,88]$. All these tools are primarily used for the energy management of microgrids.

\subsubsection{Software Tools}

Primarily, researchers throughout the world have used HOMER to optimize their suggested hybrid systems. HOMER is a computer software that can evaluate various design options for both standalone and grid-connected energy systems. Three main tasks that HOMER can perform are simulation, optimization, and sensitivity analysis [89]. Bhakta et al. [90] utilized HOMER for sizing, optimizing, and performing the economic analysis 
of a PV/wind hybrid system with a battery bank for microgrid residential application in Northeast India. In Reference [91], Das et al. carried out a feasibility study to find the optimal size combination of hybrid energy system for the household user in Kuakata, Bangladesh. Giannoulis and Haralambopoulos [92], Al-Karaghouli and Kazmerski [93], Bekele and Palm [94], Ma et al. [95], Adaramola et al. [96], Olatomiwa et al. [97], Nandi and Ghosh [98], Sen and Bhattacharya [99], and Lau et al. [100], used HOMER to optimize their proposed standalone hybrid systems. Different locations throughout the world (Nigeria, Bangladesh, Ethiopia, Iraq, Hong Kong, Ghana, India, Malaysia, and Greece) are covered. Each survey suggested a particular combination of components which is different from others in terms of performance, according to a certain location.

i-HOGA is a hybrid energy system optimization software developed by the University of Zaragoza [101]. It utilizes GA for the size optimization of single- or multi-objective functions. i-HOGA performs optimal control strategies with less computational time compared to the use of GA alone. In Reference [102], Fadaeenejad et al. used the i-HOGA software to analyze the optimal size combination for a remote village in Malaysia in terms of minimizing the amount of cost of energy and $\mathrm{CO}_{2}$ emission.

TRNSYS software can be used to simulate the behavior of transient systems. In Reference [87], Behzadi and Niasati examined a hybrid system consisting of PV, battery, and FC. In this system, TRNSYS software was used to conduct the performance analysis. The system sizing could be carried out by using the GA via i-HOGA, manual calculation, or HOMER. Authors used three different energy management strategies to dispatch energy in this hybrid system. Firstly, the value of excess energy is checked. If it is positive, the excess energy will be directed to charge the battery to its maximum SOC. The excess energy is then directed to produce more hydrogen. However, if the excess energy is negative and the SOC of the battery is less than its minimum SOC, then FC system will supply the load if the pressure in the hydrogen tank is higher than the critical value; otherwise, the battery will supply the load. In the second step, the control system never checks for the minimum SOC. It only checks for the level of pressure in the hydrogen tank. Lastly, the nominal power of each component is checked, and control system decides that how much amount of power can flow toward each storage device. A similar approach was presented in Reference [103], in which a hybrid energy system (hydrogen storage and a supercapacitor) was used as a storage system. In this paper, the aim of the proposed energy management strategy was to satisfy the load requirement. The PV panels prioritize supplying the load, and surplus energy is used to generate hydrogen. When the hydrogen storage system is filled, excess energy is directed to the supercapacitor. If the storage system is fully charged, then the solar system will be automatically shut down.

GUI integrating different algorithms is graphically used for sizing optimization and measuring system efficiency in homes and offices for residential applications. In several articles, GUI is considered as a real-time monitoring and energy management tool. In Reference [104], GUI was used to optimize the size of a hybrid PV, WT, BS, and DG system while considering the peaks and troughs of wind speed and solar irradiance for a complete year. The proposed method used the measured annual hourly solar irradiation and wind speed to simulate the real time operation of the hybrid system. In the study, authors found that the peaks of solar irradiation and wind speed affect the size optimization results.

\subsubsection{Hardware Components}

Arduino is an open-source hardware platform supportive of electronic prototyping. It has been used in different projects and had several applications. In Reference [39], authors used the Mega 2560 model to measure the temperature of PV modules by means of a network of digital temperature sensors. Arduino microcontroller has been used to verify the smart grid features [105]. In this study, a multi-agent approach was used to address the complexity issues in the microgrid network.

Raspberry $\mathrm{Pi}(\mathrm{RPi})$ is an open-source and series of small single-board computers (SBCs) developed by the Raspberry Pi Foundation of the University of Cambridge in 2012. 
It provides huge computation resources and wide connectivity options. Raspberry $\mathrm{Pi}$ features a Broadcom system on a chip with an integrated ARM cortex A72 processor and on-chip graphics processing unit (GPU). In Addition, USB 3.0 and Gigabit Ethernet ports are available. In the context of EMS, it can bring new possibilities for the integration and development of an operating system (OS). According to authors, it gives easy access to a high level of computation while providing the same input/output pins as a microcontroller [106]. In Reference [88], authors used a raspberry Pi (RPi) board to send information to a local data base for the supervisory control of a microgrid testbed. Another innovative device has been developed by Victron Energy Almere Haven (The Netherlands), i.e., color control GX (CCGX). With this device, full system control is gained by the exchange of data with solar chargers, inverters, batteries, and other connected appliances. According to the authors in Reference [39], this device is very useful for real-time operation in microgrid systems, as it provides full access to the very extensive controls and settings of all system components, such as, PV, battery, solar charger, and generator. It allows a remote user and installer to login from anywhere, at any time.

Another category of powerful, real-time simulation devices is investigated in the literature, including real-time simulators from OPAL-RT, Typhoon and dSPACE enterprises. It provides real-time simulations for electrical conversion and enables customers to conduct precise and exhaustive testing more quickly. In [99], authors designed a real-time simulation platform to simulate and control the system. In the studied system, PV panels and a WT were linked with the batteries. The objective was to control the speed of the WT and maintain the battery SOC. Authors in Reference [40], presented an intelligent EMS based on a complete supervisory control and data acquisition (SCADA) system for smart building applications. The duties were performed in an educational building with an MG Laboratory testbed, which was named LAMBDA, at the Sapienza University of Rome. The proposed model examined the daily production and consumption of different sources and loads in real time and evaluated the economic aspect.

\subsection{Energy Management Strategies Analysis}

In different control frameworks, problems can be formulated in different manners according to the objective functions and the underlying controls. Numerous energy management strategies have been discussed in the article, but few of them relate to the DC microgrid system for residential applications. Most adopted energy management strategies, such as linear programming-based EMS, artificial intelligence-based EMS, and hardware and software tool-based EMSs, such as SCADA and HOMER, are chosen with the system configuration (PV/wind/fuel cell/storage) and control objectives, and are summarized in Table 4.

The EMS-integrated DC microgrid structure is presented previously in Figure 8, consisting of PV panels and a WT connected with a storage system (e.g., batteries and supercapacitor) via power converters. All the elements are connected to the common DC bus. Regarding the DC microgrid system, a few similar systems identified in the literature are presented in Table 5, with their element characterizations and corresponding EMS. It should be noted that no single method can satisfy all the requirements, and hybrid methods may be used in combination in an EMS. 
Table 4. Summary of EMS strategies.

\begin{tabular}{|c|c|c|}
\hline System Configuration & EMS Approach & Control Objectives \\
\hline PV/Wind/Fuel cell/Battery & Fuzzy logic (FL) [47] & $\begin{array}{l}\text { Satisfy the load demand while } \\
\text { maintaining the battery SOC and } \\
\text { keeping the hydrogen storage tank at } \\
\text { maximum level. } \\
\text { Cost optimization. }\end{array}$ \\
\hline PV/Wind/Fuel cell/Battery & $\begin{array}{l}\text { Linear programming } \\
\text { (LP) [56] }\end{array}$ & $\begin{array}{l}\text { Reduce the computational time. } \\
\text { Minimize the energy cost and } \mathrm{CO}_{2} \\
\text { emissions. } \\
\text { Increase the battery life. }\end{array}$ \\
\hline PV/Fuel cell/Battery & $\begin{array}{l}\text { Model predictive } \\
\text { control (MPC) [57] }\end{array}$ & $\begin{array}{l}\text { Weather forecasts. } \\
\text { Optimize microgrid operation while } \\
\text { considering uncertainties of RERs } \\
\text { and load demand. } \\
\text { Minimize the daily generation cot } \\
\text { and emission. }\end{array}$ \\
\hline PV/Battery/Fuel cell & $\begin{array}{l}\text { Linear programming } \\
\text { (LP) [61] }\end{array}$ & Battery overcharging protection. \\
\hline $\begin{array}{l}\text { Hybrid renewable energy } \\
\text { sources based on storage } \\
\text { systems integrated } \\
\text { with a grid. }\end{array}$ & Fuzzy logic (FL) [72] & $\begin{array}{l}\text { Optimization and design of control } \\
\text { strategy: power, energy efficiency, } \\
\text { economic evaluation, environmental } \\
\text { effects, and voltage quality. }\end{array}$ \\
\hline PV/Wind/Fuel cell/Battery & Fuzzy logic (FL) [73] & $\begin{array}{l}\text { Regulate the overall system power } \\
\text { flow. } \\
\text { Batteries' life cycle. }\end{array}$ \\
\hline $\begin{array}{l}\text { Standalone and } \\
\text { grid-connected system with } \\
\text { different configurations. }\end{array}$ & HOMMER $[85,86]$ & $\begin{array}{l}\text { Making energy balance calculations } \\
\text { on an hourly basis for a complete year. } \\
\text { Size optimization of each component } \\
\text { to achieve the minimum cost of } \\
\text { energy production. }\end{array}$ \\
\hline
\end{tabular}

Table 5. Analysis of EMS strategies with element characterization.

\begin{tabular}{cccc}
\hline \multicolumn{5}{c}{$\begin{array}{c}\text { Intelligent EMS based on SCADA system [40] } \\
\text { (MATLAB/Simulink integrated with Modbus and Konnex) }\end{array}$} \\
\hline System Element & Type & Capacity & Objective \\
\hline PV Panels & Monocrystalline & $5 \mathrm{~kW}$ & MPPT \\
\hline Battery & Li-ion & $6.5 \mathrm{kWh}$ & Charging/discharging \\
\hline Load & \multicolumn{4}{c}{. } & RW & Reveals daily consumption \\
\hline \multicolumn{5}{c}{ EMS with fuzzy control for a DC microgrid system [72] } \\
\hline System Element & Type & Capacity & Objective \\
\hline PV panels & Monocrystalline & $5 \mathrm{~kW}$ & MPPT \\
\hline Wind Turbine & AWV 1500 & $1.5 \mathrm{~kW}$ & MPPT \\
\hline Battery & Li-ion & $1.5 \mathrm{kWh}$ & SOC \\
\hline Load & & $6.5 \mathrm{~kW}$ & \\
\hline DC bus voltage & & $380 \mathrm{~V}( \pm 20 \mathrm{~V})$ & \\
\hline
\end{tabular}


Table 5. Cont.

Intelligent EMS based on SCADA system [40]

(MATLAB/Simulink integrated with Modbus and Konnex)

\begin{tabular}{|c|c|c|c|}
\hline System Element & Type & Capacity & Objective \\
\hline \multicolumn{4}{|c|}{$\begin{array}{l}\text { EMS for islanded microgrid based on rule-based power flow control [54] } \\
\text { (PSCAD simulation tool) }\end{array}$} \\
\hline System Element & Type & Capacity & Objective \\
\hline PV panels & Monocrystalline & $30 \mathrm{~kW}$ & MPPT \\
\hline Wind Turbine & & $3 \mathrm{~kW}$ & MPPT \\
\hline Battery pack & $\begin{array}{l}\text { Li-ion } \\
\text { Lead Acid }\end{array}$ & $800 \mathrm{Ah}$ & $\mathrm{SOC}$ \\
\hline Load & $(10 \mathrm{~kW}+15 \mathrm{~kW})$ & $25 \mathrm{~kW}$ & \\
\hline \multicolumn{4}{|c|}{$\begin{array}{l}\text { EMS for residential microgrid system based on NN and MILP [66] } \\
\text { (Neural network and Mixed integer linear programming algorithm) }\end{array}$} \\
\hline System Element & Type & Capacity & Objective \\
\hline PV panels & & $6 \mathrm{~kW}$ & MPPT \\
\hline Battery & Li-ion & $5.8 \mathrm{kWh}$ & SOC \\
\hline
\end{tabular}

EMS for real time laboratory control based on feedback \& PI cascaded control [107] (MATLAB/Simulink integrated with RT-LAB tool)

\begin{tabular}{cccc}
\hline System Element & Type & Capacity & Objective \\
\hline PV panels & & $260 \mathrm{~W}$ & MPPT \\
\hline Wind Turbine & PMSG & $260 \mathrm{~W}$ & Speed/torque \\
\hline Battery & Lead acid & $10 \mathrm{Ah}$ & SOC \\
\hline DC bus voltage & & $20 \mathrm{~V}$ & \\
\hline
\end{tabular}

Intelligent EMS with linear programming based multi-objective optimization [108] (Artificial neural network and Fuzzy logic controller)

\begin{tabular}{cccc}
\hline System Element & Type & Capacity & Objective \\
\hline PV panels & & $20 \mathrm{~kW}$ & Cost minimization \\
\hline Wind Turbine & & $25 \mathrm{~kW}$ & Cost minimization \\
\hline Battery & Lead acid & $15 \mathrm{kWh}$ & SOC \\
\hline Fuel cell & & $15 \mathrm{~kW}$ & Cost minimization \\
\hline
\end{tabular}

EMS with multi-agent system [109]

(MATLAB/Simulink tool)

\begin{tabular}{cccc}
\hline System Element & Type & Capacity & Objective \\
\hline PV panels & Titan S-60 & $100 \mathrm{~kW}$ & MPPT \\
\hline Wind Turbine & PMSG & $200 \mathrm{~kW}$ & MPPT \\
\hline Battery & Lead acid & $300 \mathrm{kWh}$ & SOC \\
\hline Load & & $80 \mathrm{~kW}$ & \\
\hline
\end{tabular}

The review has classified different methods for the energy management of microgrid systems coupled with various RES and storage systems. Tables 4 and 5 have summarized the research conducted in comparing several algorithms and techniques used for size optimization and EMS. In Table 5, more specifications are given on the existing microgrid systems in the literature with their element characterization, and different EMS strategies.

The cited articles related to the EMS of a DC microgrid for residential applications in this review paper are 74 in total; among them, 73\% (54 articles) were published during the period of 2015-2021, and 27\% (20 articles) were published during the years 2010-2014. A 
growing trend has been observed regarding EMS design and implementation in the DC microgrid domain in recent years, especially after the year 2015. A graphical representation of the references in years is illustrated in Figure 10.

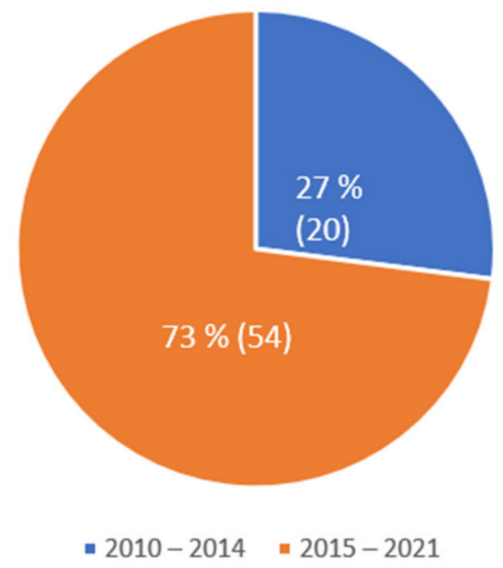

Figure 10. Citation graphical representation in years.

\section{Discussion}

The previous reviews have mainly focused on the AC or hybrid AC/DC microgrid systems (islanded/grid-connected mode) which comprise several DERs and storage elements. The DC microgrid system has not been specifically addressed, especially for residential applications. It is thus interesting to have an overview of its different aspects, such as the architecture design, control design, communication technologies and EMS.

For residential applications, 380-400 V DC could be an appropriate voltage level for the common DC bus based on a synthesis of different appliances' voltage levels and their power ranges. Apart from the common DC bus voltage level, a variance of DC voltage standards, such as $12 \mathrm{~V}, 24 \mathrm{~V}$ and $48 \mathrm{~V}$ can be defined according to different appliance groups, as summarized in Tables 1 and 2. Reasonable design of a set of DC voltage levels may favor the system efficiency, reduce the power losses due to the high step-up ratio and many conversion stages, and augment the users' safety as lower DC voltage levels are applied. In future studies, further quantitative analysis could be conducted for setting variant DC voltage standards dedicated to residential applications.

For the microgrid communication technologies, the communication links in rural and residential area microgrids mainly depend on the cost and data rate. Nowadays, wired technologies still dominate in microgrids due to the existing hardware components and the relatively mature communication techniques and protocols. An increase in wireless technologies has been observed in recent years due to their low deployment cost, high flexibility, and low power consumption. Different communication standards and protocols exist for both technologies. The interoperability among the different standards will be an essential part of information and communication technology (ICT) in order to modernize the microgrid and make it truly smart. In recent years, concepts such as the internet of things (IoT), block chains and cyber-physical microgrid, have been much focused on, which indicate the importance of the ICT aspect.

The energy management of a DC microgrid system for residential applications has been specifically emphasized in this review. For the microgrid EMS, it can be noticed that a growing trend is observed towards the use of artificial intelligence methods for the optimization and energy management of the system, due to their inherent advantages in dealing with complex multi-objective optimization problems. It should be noted that no single method can meet all the requirements of an EMS. Hybrid methods can be combinedly used for a practical EMS. In addition, in more recent articles, predictive functions have been integrated into the EMS design to consider the influences of factors such as future energy generation, load demand, and energy market variation in hours or even days ahead. 
Another aspect is that apart from EMSs, health management strategies (HMS) should be equally considered, including the degradation cost for each component (e.g., battery degradation cost), the PV shading cost (e.g., the shading effect on PV panels), and the reliability of the converters (e.g., the degradation effect of the switching devices). An interaction of both EMSs and HMS could be valuable for both an efficient and reliable operation of the microgrids.

\section{Conclusions}

Compared with the traditionally used AC microgrid and hybrid AC/DC microgrid, the DC type has advantages in terms of system efficiency, reliability, and cost. Nevertheless, various issues, such as its protection system, architecture design, control strategies and stabilization techniques, deserve tremendous research efforts. This paper has specifically reviewed several critical issues regarding DC microgrids in residential applications, including their architecture design, communication technologies, control structure and EMS classifications.

Concerning its architecture, the DC bus level of $380-400 \mathrm{~V}$ has been considered as an appropriate voltage level for the common DC bus, considering the different voltage levels and power ranges of residential appliances. However, different DC voltage standards may exist in the future microgrid to further improve the system efficiency and reduce the power conversion stages. The communication technologies have also been briefly discussed, including both wired and wireless technologies. Compared with the dominant wired technologies, the wireless type has generated more interest due to its low deployment cost, high flexibility, and low power consumption. As illustrated in the discussion part, the ICT part will be essential to constructing modern and smart microgrids. Tremendous effort is still needed in the future.

Particular attention has been paid to the EMS issues in the tertiary level specifically for residential applications. Two major categories have been summarized, including classical and artificial intelligence methods. According to the literature research, classical methods have been majorly applied for solving optimization problems. Iterative algorithm, linear programming, mixed-integer linear programming, stochastic and robust programming, and model predictive control in this category have been briefly introduced. Artificial intelligence methods, including fuzzy logic, neural network, evolutionary computation methods together with multi-agent system, have gained popularity for the multi-objective energy management of microgrids. In this category, advanced techniques are used to solve single-objective optimization (SOO) and multi-objective optimization (MOO) problems. In general, they are more flexible and efficient in dealing with complex optimization problems. In addition, in recent publications, the predictive functions on future energy generation, low demand and energy market variation and so on have been integrated into the EMS. Health management strategies (HMS) considering the degradation cost and the reliability of each component have also been integrated into the EMS objective functions. The interaction of EMSs and HMS could be an interesting research direction to guarantee the efficient and reliable operation of DC microgrids.

Some existing software tools have also been listed, such as HOMER, i-HOGA and TRANSYS, which could be interesting for residential end users due to their good interpretability. Final analysis has been carried out based on several examples of DC microgrids for residential applications, including the system elements with their types and power levels, the controlling objective of each part and the overall EMS. They could provide some concrete examples for future designers of DC microgrids for residential applications.

Author Contributions: S.A., Z.Z. and M.A. for conceptualization; S.A. for writing the original draft; Z.Z. for writing and reviewing; M.A., J.-P.S., M.-C.P. and D.H. for reviewing and further modifications. The revised version has received the agreement of all the authors. All authors have read and agreed to the published version of the manuscript.

Funding: This research was funded by French National Agency for Research (ANR). 
Acknowledgments: The authors would like to acknowledge that the work has been done within the framework of ANR JCJC EREMITE project with the agreement number (ANR-19-CE05-0008-01).

Conflicts of Interest: The authors declare no conflict of interest.

\section{References}

1. European Commission. 2030 Climate \& Energy Framework. Available online: https://Ec.Europa.Eu/Clima/Policies/Strategies/ 2030_en (accessed on 30 September 2020).

2. REN21. Renewables 2021 Global Status Report; REN21 Secretariat: Paris, France, 2021; ISBN 978-3-948393-03-8.

3. IEA. Global Energy Review the Impacts of the Covid-19 Crisis on Global Energy Demand and CO2 Emissions. 2020. Available online: https:/ / www.Iea.Org/Reports/Global-Energy-Review-2020 (accessed on 31 May 2020).

4. Planas, E.; Andreu, J.; Gárate, J.I.; Martínez de Alegría, I.; Ibarra, E. AC and DC Technology in Microgrids: A Review. Reneww. Sustain. Energy Rev. 2015, 43, 726-749. [CrossRef]

5. Lidula, N.W.A.; Rajapakse, A.D. Microgrids Research: A Review of Experimental Microgrids and Test Systems. Renew. Sustain. Energy Rev. 2011, 15, 186-202. [CrossRef]

6. Linden, D.; Reddy, T. Handbook of Batteries, 3rd ed; McGraw-Hill Professional: New York, NY, USA, 2001.

7. González, A.; Goikolea, E.; Barrena, J.A.; Mysyk, R. Review on Supercapacitors: Technologies and Materials. Renew. Sustain. Energy Rev. 2016, 58, 1189-1206. [CrossRef]

8. Hossain, E.; Kabalci, E.; Bayindir, R.; Perez, R. Microgrid Testbeds around the World: State of Art. Energy Convers. Manag. 2014, 86, 132-153. [CrossRef]

9. Igualada, L.; Corchero, C.; Cruz-Zambrano, M.; Heredia, F. Optimal Energy Management for a Residential Microgrid Including a Vehicle-to-Grid System. IEEE Trans. Smart Grid 2014, 5, 2163-2172. [CrossRef]

10. Arefifar, S.A.; Ordonez, M.; Mohamed, Y.A.-R.I. Energy Management in Multi-Microgrid Systems—Development and Assessment. IEEE Trans. Power Syst. 2017, 32, 910-922. [CrossRef]

11. Helal, S.A.; Najee, R.J.; Hanna, M.O.; Shaaban, M.F.; Osman, A.H.; Hassan, M.S. An Energy Management System for Hybrid Microgrids in Remote Communities. In Proceedings of the 2017 IEEE 30th Canadian Conference on Electrical and Computer Engineering (CCECE), Windsor, ON, Canada, 30 April-3 May 2017; pp. 1-4.

12. Pascual, J.; Barricarte, J.; Sanchis, P.; Marroyo, L. Energy Management Strategy for a Renewable-Based Residential Microgrid with Generation and Demand Forecasting. Appl. Energy 2015, 158, 12-25. [CrossRef]

13. Leonori, S.; Martino, A.; Frattale Mascioli, F.M.; Rizzi, A. Microgrid Energy Management Systems Design by Computational Intelligence Techniques. Appl. Energy 2020, 277, 115524. [CrossRef]

14. Fontenot, H.; Dong, B. Modeling and Control of Building-Integrated Microgrids for Optimal Energy Management-A Review. Appl. Energy 2019, 254, 113689. [CrossRef]

15. Zia, M.F.; Elbouchikhi, E.; Benbouzid, M. Microgrids Energy Management Systems: A Critical Review on Methods, Solutions, and Prospects. Appl. Energy 2018, 222, 1033-1055. [CrossRef]

16. Coelho, V.N.; Weiss Cohen, M.; Coelho, I.M.; Liu, N.; Guimarães, F.G. Multi-Agent Systems Applied for Energy Systems Integration: State-of-the-Art Applications and Trends in Microgrids. Appl. Energy 2017, 187, 820-832. [CrossRef]

17. Al-Falahi, M.D.A.; Jayasinghe, S.D.G.; Enshaei, H. A Review on Recent Size Optimization Methodologies for Standalone Solar and Wind Hybrid Renewable Energy System. Energy Convers. Manag. 2017, 143, 252-274. [CrossRef]

18. Meng, L.; Sanseverino, E.R.; Luna, A.; Dragicevic, T.; Vasquez, J.C.; Guerrero, J.M. Microgrid Supervisory Controllers and Energy Management Systems: A Literature Review. Renew. Sustain. Energy Rev. 2016, 60, 1263-1273. [CrossRef]

19. Fathima, A.H.; Palanisamy, K. Optimization in Microgrids with Hybrid Energy Systems-A Review. Renew. Sustain. Energy Rev. 2015, 45, 431-446. [CrossRef]

20. Ahmad Khan, A.; Naeem, M.; Iqbal, M.; Qaisar, S.; Anpalagan, A. A Compendium of Optimization Objectives, Constraints, Tools and Algorithms for Energy Management in Microgrids. Renew. Sustain. Energy Rev. 2016, 58, 1664-1683. [CrossRef]

21. Olatomiwa, L.; Mekhilef, S.; Ismail, M.S.; Moghavvemi, M. Energy Management Strategies in Hybrid Renewable Energy Systems: A Review. Renew. Sustain. Energy Rev. 2016, 62, 821-835. [CrossRef]

22. Khare, V.; Nema, S.; Baredar, P. Solar-Wind Hybrid Renewable Energy System: A Review. Renew. Sustain. Energy Rev. 2016, 58, 23-33. [CrossRef]

23. Gamarra, C.; Guerrero, J.M. Computational Optimization Techniques Applied to Microgrids Planning: A Review. Renew. Sustain. Energy Rev. 2015, 48, 413-424. [CrossRef]

24. Elmouatamid, A.; Ouladsine, R.; Bakhouya, M.; El Kamoun, N.; Khaidar, M.; Zine-Dine, K. Review of Control and Energy Management Approaches in Micro-Grid Systems. Energies 2021, 14, 168. [CrossRef]

25. Torres-Moreno, J.L.; Gimenez-Fernandez, A.; Perez-Garcia, M.; Rodriguez, F. Energy Management Strategy for Micro-Grids with PV-Battery Systems and Electric Vehicles. Energies 2018, 11, 522. [CrossRef]

26. Yang, N.; Nahid-Mobarakeh, B.; Gao, F.; Paire, D.; Miraoui, A.; Liu, W. Modeling and Stability Analysis of Multi-Time Scale DC Microgrid. Electr. Power Syst. Res. 2016, 140, 906-916. [CrossRef]

27. Dragičević, T.; Lu, X.; Vasquez, J.C.; Guerrero, J.M. DC Microgrids-Part I: A Review of Control Strategies and Stabilization Techniques. IEEE Trans. Power Electron. 2016, 31, 4876-4891. [CrossRef] 
28. Wu, X.; Wang, Z.; Ding, T.; Li, Z. Hybrid AC/DC Microgrid Planning with Optimal Placement of DC Feeders. Energies 2019, 12, 1751. [CrossRef]

29. Moussa, S.; Ghorbal, M.J.-B.; Slama-Belkhodja, I. Bus Voltage Level Choice for Standalone Residential DC Nanogrid. Sustain. Cities Soc. 2019, 46, 101431. [CrossRef]

30. Manavalan, G.; Tania, H.M.; Patra, J.K.; Poongothai, M.G.; Prema, S. A Closed Loop System to Stabilize a 24 V Solar DC Nano Grid. In Proceedings of the 2017 International Conference on Smart grids, Power and Advanced Control Engineering (ICSPACE), Bangalore, India, 17-19 August 2017; pp. 177-182.

31. Noritake, M.; Yuasa, K.; Takeda, T.; Shimomachi, K.; Hara, R.; Kita, H.; Matsumura, T. Experimental Study of a 400 V Class DC Microgrid for Commercial Buildings. In Proceedings of the 2015 9th International Conference on Power Electronics and ECCE Asia (ICPE-ECCE Asia), Seoul, Korea, 1-5 June 2015; pp. 1730-1735.

32. Lin, X.; Xue, Y.; Song, C.; Song, S.; Bin, L. An Experiment and Research Platform for DC Micro-Grid. In Proceedings of the 2016 35th Chinese Control Conference (CCC), Chengdu, China, 27-29 July 2016; pp. 8588-8595.

33. Sabry, A.H.; Shallal, A.H.; Hameed, H.S.; Ker, P.J. Compatibility of Household Appliances with DC Microgrid for PV Systems. Heliyon 2020, 6, e05699. [CrossRef]

34. Decuir, J.; Michael, P. Draft IEEE Standard for DC Microgrids for Rural and Remote Electricity Access Applications. In Proceedings of the 2017 IEEE Conference on Technologies for Sustainability (SusTech), Phoenix, AZ, USA, 12-14 November 2017; pp. 1-5.

35. Kamran, M.; Bilal, M.; Mudassar, M. DC Home Appliances for DC Distribution System. Mehran Univ. Res. J. Eng. Technol. 2017, 36, 881-890. [CrossRef]

36. Ramezy, B.; Saadatmand, M.; Mozafari, B. Review of Communication Technologies for Smart Grid applications. In Proceedings of the National Conference on: New Approaches in Power Industry, Tehran, Iran, 31 October 2017.

37. Bani-Ahmed, A.; Weber, L.; Nasiri, A.; Hosseini, H. Microgrid Communications: State of the Art and Future Trends. In Proceedings of the 2014 International Conference on Renewable Energy Research and Application (ICRERA), Milwaukee, WI, USA, 19-22 October 2014; pp. 780-785.

38. Emmanuel, M.; Rayudu, R. Communication Technologies for Smart Grid Applications: A Survey. J. Netw. Comput. Appl. 2016, 74, 133-148. [CrossRef]

39. González, I.; Calderón, A.J.; Portalo, J.M. Innovative Multi-Layered Architecture for Heterogeneous Automation and Monitoring Systems: Application Case of a Photovoltaic Smart Microgrid. Sustainability 2021, 13, 2234. [CrossRef]

40. Kermani, M.; Adelmanesh, B.; Shirdare, E.; Sima, C.A.; Carnì, D.L.; Martirano, L. Intelligent Energy Management Based on SCADA System in a Real Microgrid for Smart Building Applications. Renew. Energy 2021, 171, 1115-1127. [CrossRef]

41. Nguyen, T.L.; Tran, Q.-T.; Caire, R.; Gavriluta, C.; Nguyen, V.H. Agent Based Distributed Control of Islanded Microgrid-RealTime Cyber-Physical Implementation. In Proceedings of the 2017 IEEE PES Innovative Smart Grid Technologies Conference Europe (ISGT-Europe), Torino, Italy, 26-29 September 2017; pp. 1-6.

42. Singh, P.; Paliwal, P.; Arya, A. A Review on Challenges and Techniques for Secondary Control of Microgrid. IOP Conf. Ser. Mater. Sci. Eng. 2019, 561, 012075. [CrossRef]

43. Huang, W.; Lu, M.; Zhang, L. Survey on Microgrid Control Strategies. Energy Procedia 2011, 12, 206-212. [CrossRef]

44. Justo, J.J.; Mwasilu, F.; Lee, J.; Jung, J.-W. AC-Microgrids versus DC-Microgrids with Distributed Energy Resources: A Review. Renew. Sustain. Energy Rev. 2013, 24, 387-405. [CrossRef]

45. Meng, L.; Luna, A.; Díaz, E.R.; Sun, B.; Dragicevic, T.; Savaghebi, M.; Vasquez, J.C.; Guerrero, J.M.; Graells, M.; Andrade, F. Flexible System Integration and Advanced Hierarchical Control Architectures in the Microgrid Research Laboratory of Aalborg University. IEEE Trans. Ind. Appl. 2016, 52, 1736-1749. [CrossRef]

46. Guerrero, J.M.; Vasquez, J.C.; Matas, J.; de Vicuna, L.G.; Castilla, M. Hierarchical Control of Droop-Controlled AC and DC Microgrids-A General Approach toward Standardization. IEEE Trans. Ind. Electron. 2011, 58, 158-172. [CrossRef]

47. García, P.; Torreglosa, J.P.; Fernández, L.M.; Jurado, F. Optimal Energy Management System for Stand-Alone Wind Turbine/Photovoltaic/Hydrogen/Battery Hybrid System with Supervisory Control Based on Fuzzy Logic. Int. J. Hydrog. Energy 2013, 38, 14146-14158. [CrossRef]

48. Wang, Y.; Chen, C.; Wang, J.; Baldick, R. Research on Resilience of Power Systems under Natural Disasters-A Review. IEEE Trans. Power Syst. 2016, 31, 1604-1613. [CrossRef]

49. Hirsch, A.; Parag, Y.; Guerrero, J. Microgrids: A Review of Technologies, Key Drivers, and Outstanding Issues. Renew. Sustain. Energy Rev. 2018, 90, 402-411. [CrossRef]

50. Feng, X.; Shekhar, A.; Yang, F.; Hebner, R.E.; Bauer, P. Comparison of Hierarchical Control and Distributed Control for Microgrid. Electr. Power Compon. Syst. 2017, 45, 1043-1056. [CrossRef]

51. Minchala-Avila, L.I.; Garza-Castañón, L.E.; Vargas-Martínez, A.; Zhang, Y. A Review of Optimal Control Techniques Applied to the Energy Management and Control of Microgrids. Procedia Comput. Sci. 2015, 52, 780-787. [CrossRef]

52. Li, Y.; Nejabatkhah, F. Overview of Control, Integration and Energy Management of Microgrids. J. Mod. Power Syst. Clean Energy 2014, 2, 212-222. [CrossRef]

53. El Alimi, S.; Maatallah, T.; Ben Nasrallah, S. Break-Even Analysis and Optimization of a Stand-Alone Hybrid System with Battery Storage for Residential Load Consumption-A Case Study. Renew. Sustain. Energy Rev. 2014, 37, 408-423. [CrossRef]

54. Zhang, Y.; Jia, H.J.; Guo, L. Energy Management Strategy of Islanded Microgrid Based on Power Flow Control. In Proceedings of the 2012 IEEE PES Innovative Smart Grid Technologies (ISGT), Washington, DC, USA, 16-20 January 2012; pp. 1-8. 
55. Xu, L.; Ruan, X.; Mao, C.; Zhang, B.; Luo, Y. An Improved Optimal Sizing Method for Wind-Solar-Battery Hybrid Power System. IEEE Trans. Sustain. Energy 2013, 4, 774-785. [CrossRef]

56. Torreglosa, J.P.; García-Triviño, P.; Fernández-Ramirez, L.M.; Jurado, F. Control Based on Techno-Economic Optimization of Renewable Hybrid Energy System for Stand-Alone Applications. Expert Syst. Appl. 2016, 51, 59-75. [CrossRef]

57. Bruni, G.; Cordiner, S.; Mulone, V.; Rocco, V.; Spagnolo, F. A Study on the Energy Management in Domestic Micro-Grids Based on Model Predictive Control Strategies. Energy Convers. Manag. 2015, 102, 50-58. [CrossRef]

58. Hosseinalizadeh, R.; Shakouri, G.H.; Amalnick, M.S.; Taghipour, P. Economic Sizing of a Hybrid (PV-WT-FC) Renewable Energy System (HRES) for Stand-Alone Usages by an Optimization-Simulation Model: Case Study of Iran. Renew. Sustain. Energy Rev. 2016, 54, 139-150. [CrossRef]

59. Bhuiyan, F.A.; Yazdani, A.; Primak, S.L. Optimal Sizing Approach for Islanded Microgrids. IET Renew. Power Gener. 2015, 9 , 166-175. [CrossRef]

60. Nogueira, C.E.C.; Vidotto, M.L.; Niedzialkoski, R.K.; de Souza, S.N.M.; Chaves, L.I.; Edwiges, T.; dos Santos, D.B.; Werncke, I. Sizing and Simulation of a Photovoltaic-Wind Energy System Using Batteries, Applied for a Small Rural Property Located in the South of Brazil. Renew. Sustain. Energy Rev. 2014, 29, 151-157. [CrossRef]

61. Dash, V.; Bajpai, P. Power Management Control Strategy for a Stand-Alone Solar Photovoltaic-Fuel Cell-Battery Hybrid System. Sustain. Energy Technol. Assess. 2015, 9, 68-80. [CrossRef]

62. Indu Rani, B.; Saravana Ilango, G.; Nagamani, C. Control Strategy for Power Flow Management in a PV System Supplying DC Loads. IEEE Trans. Ind. Electron. 2013, 60, 3185-3194. [CrossRef]

63. Battistelli, C.; Baringo, L.; Conejo, A.J. Optimal Energy Management of Small Electric Energy Systems Including V2G Facilities and Renewable Energy Sources. Electr. Power Syst. Res. 2012, 92, 50-59. [CrossRef]

64. Karami, N.; Moubayed, N.; Outbib, R. Energy Management for a PEMFC-PV Hybrid System. Energy Convers. Manag. 2014, 82, 154-168. [CrossRef]

65. Sukumar, S.; Mokhlis, H.; Mekhilef, S.; Naidu, K.; Karimi, M. Mix-Mode Energy Management Strategy and Battery Sizing for Economic Operation of Grid-Tied Microgrid. Energy 2017, 118, 1322-1333. [CrossRef]

66. Comodi, G.; Giantomassi, A.; Severini, M.; Squartini, S.; Ferracuti, F.; Fonti, A.; Nardi Cesarini, D.; Morodo, M.; Polonara, F Multi-Apartment Residential Microgrid with Electrical and Thermal Storage Devices: Experimental Analysis and Simulation of Energy Management Strategies. Appl. Energy 2015, 137, 854-866. [CrossRef]

67. Teimourzadeh Baboli, P.; Shahparasti, M.; Moghaddam, M.; Haghifam, M.-R.; Mohamadian, M. Energy Management and Operation Modeling of Hybrid AC-DC Microgrid. Gener. Transm. Distrib. IET 2014, 8, 1700-1711. [CrossRef]

68. Hu, M.-C.; Lu, S.-Y.; Chen, Y.-H. Stochastic Programming and Market Equilibrium Analysis of Microgrids Energy Management Systems. Energy 2016, 113, 662-670. [CrossRef]

69. Solanki, B.V.; Raghurajan, A.; Bhattacharya, K.; Cañizares, C.A. Including Smart Loads for Optimal Demand Response in Integrated Energy Management Systems for Isolated Microgrids. IEEE Trans. Smart Grid 2017, 8, 1739-1748. [CrossRef]

70. Prodan, I.; Zio, E. A Model Predictive Control Framework for Reliable Microgrid Energy Management. Int. J. Electr. Power Energy Syst. 2014, 61, 399-409. [CrossRef]

71. Akter, M.N.; Mahmud, M.A.; Oo, A.M.T. A Hierarchical Transactive Energy Management System for Microgrids. In Proceedings of the 2016 IEEE Power and Energy Society General Meeting (PESGM), Boston, MA, USA, 17-21 July 2016; pp. 1-5.

72. Chen, Y.-K.; Wu, Y.-C.; Song, C.-C.; Chen, Y.-S. Design and Implementation of Energy Management System with Fuzzy Control for DC Microgrid Systems. IEEE Trans. Power Electron. 2013, 28, 1563-1570. [CrossRef]

73. Erdinc, O.; Elma, O.; Uzunoglu, M.; Selamogullari, U.S.; Vural, B.; Ugur, E.; Boynuegri, A.R.; Dusmez, S. Experimental Performance Assessment of an Online Energy Management Strategy for Varying Renewable Power Production Suppression. Int. J. Hydrog. Energy 2012, 37, 4737-4748. [CrossRef]

74. Wang, T.; He, X.; Deng, T. Neural Networks for Power Management Optimal Strategy in Hybrid Microgrid. Neural Comput. Appl. 2019, 31, 2635-2647. [CrossRef]

75. Venayagamoorthy, G.K.; Sharma, R.K.; Gautam, P.K.; Ahmadi, A. Dynamic Energy Management System for a Smart Microgrid. IEEE Trans. Neural Netw. Learn. Syst. 2016, 27, 1643-1656. [CrossRef] [PubMed]

76. Energy Management System Application Program Interface (EMS-API). IEC. 2005. Available online: https://cdn.standards.iteh. ai/samples/15973/7f44c23d078a4d20b3ed6d0671b1df77/SIST-TS-CLC-TS-61970-2-2005.pdf (accessed on 7 December 2005).

77. Jifang, A.L.; Tianhao, B.T.; Jingang, C.H. A Neural Network Control Strategy for Multi-Energy Common Dc Bus Hybrid Power Supply. In Proceedings of the SPEEDAM 201, Pisa, Italy, 14-16 June 2010; pp. 1827-1831.

78. Ogunjuyigbe, A.S.O.; Ayodele, T.R.; Akinola, O.A. Optimal Allocation and Sizing of PV/Wind/Split-Diesel/Battery Hybrid Energy System for Minimizing Life Cycle Cost, Carbon Emission and Dump Energy of Remote Residential Building. Appl. Energy 2016, 171, 153-171. [CrossRef]

79. Rajanna, S.; Saini, R.P. Development of Optimal Integrated Renewable Energy Model with Battery Storage for a Remote Indian Area. Energy 2016, 111, 803-817. [CrossRef]

80. Kamjoo, A.; Maheri, A.; Dizqah, A.M.; Putrus, G.A. Multi-Objective Design under Uncertainties of Hybrid Renewable Energy System Using NSGA-II and Chance Constrained Programming. Int. J. Electr. Power Energy Syst. 2016, 74, 187-194. [CrossRef]

81. Sheng, W.; Liu, K.; Meng, X.; Ye, X.; Liu, Y. Research and Practice on Typical Modes and Optimal Allocation Method for PV-Wind-ES in Microgrid. Electr. Power Syst. Res. 2015, 120, 242-255. [CrossRef] 
82. Suhane, P.; Rangnekar, S.; Mittal, A.; Khare, A. Sizing and Performance Analysis of Standalone Wind-Photovoltaic Based Hybrid Energy System Using Ant Colony Optimisation. IET Renew. Power Gener. 2016, 10, 964-972. [CrossRef]

83. Zhao, J.; Yuan, X. Multi-Objective Optimization of Stand-Alone Hybrid PV-Wind-Diesel-Battery System Using Improved Fruit Fly Optimization Algorithm. Soft Comput. 2016, 20, 2841-2853. [CrossRef]

84. Anvari-Moghaddam, A.; Rahimi-Kian, A.; Mirian, M.S.; Guerrero, J.M. A Multi-Agent Based Energy Management Solution for Integrated Buildings and Microgrid System. Appl. Energy 2017, 203, 41-56. [CrossRef]

85. NREL. HOMER. 2010. Available online: https://www.nrel.gov/docs/fy10osti/45630.pdf (accessed on 31 January 2010).

86. Mahesh, A.; Sandhu, K.S. Hybrid Wind/Photovoltaic Energy System Developments: Critical Review and Findings. Renew. Sustain. Energy Rev. 2015, 52, 1135-1147. [CrossRef]

87. Behzadi, M.S.; Niasati, M. Comparative Performance Analysis of a Hybrid PV/FC/Battery Stand-Alone System Using Different Power Management Strategies and Sizing Approaches. Int. J. Hydrog. Energy 2015, 40, 538-548. [CrossRef]

88. Vargas-Salgado, C.; Aguila-Leon, J.; Chiñas-Palacios, C.; Hurtado-Perez, E. Low-Cost Web-Based Supervisory Control and Data Acquisition System for a Microgrid Testbed: A Case Study in Design and Implementation for Academic and Research Applications. Heliyon 2019, 5, e02474. [CrossRef] [PubMed]

89. Lambert, T.; Gilman, P.; Lilienthal, P. Micropower System Modeling with Homer. In Integration of Alternative Sources of Energy; Farret, F.A., Simões, M.G., Eds.; John Wiley \& Sons, Inc.: Hoboken, NJ, USA, 2006; pp. 379-418. ISBN 978-0-471-75562-3.

90. Bhakta, S.; Mukherjee, V.; Shaw, B. Techno-Economic Analysis and Performance Assessment of Standalone Photovoltaic/Wind/Hybrid Power System in Lakshadweep Islands of India. J. Renew. Sustain. Energy 2015, 7, 063117. [CrossRef]

91. Das, H.S.; Dey, A.; Wei, T.C.; Yatim, A.H.M. Feasibility Analysis of Standalone PV/Wind/Battery Hybrid Energy System for Rural Bangladesh. Int. J. Renew. Energy Res. 2016, 6, 402-412.

92. Giannoulis, E.D.; Haralambopoulos, D.A. Distributed Generation in an Isolated Grid: Methodology of Case Study for LesvosGreece. Appl. Energy 2011, 88, 2530-2540. [CrossRef]

93. Al-Karaghouli, A.; Kazmerski, L.L. Optimization and Life-Cycle Cost of Health Clinic PV System for a Rural Area in Southern Iraq Using HOMER Software. Sol. Energy 2010, 84, 710-714. [CrossRef]

94. Bekele, G.; Palm, B. Feasibility Study for a Standalone Solar-Wind-Based Hybrid Energy System for Application in Ethiopia. Appl. Energy 2010, 87, 487-495. [CrossRef]

95. Ma, T.; Yang, H.; Lu, L. Study on Stand-Alone Power Supply Options for an Isolated Community. Int. J. Electr. Power Energy Syst. 2015, 65, 1-11. [CrossRef]

96. Adaramola, M.S.; Agelin-Chaab, M.; Paul, S.S. Analysis of Hybrid Energy Systems for Application in Southern Ghana. Energy Convers. Manag. 2014, 88, 284-295. [CrossRef]

97. Olatomiwa, L.; Mekhilef, S.; Huda, A.S.N.; Ohunakin, O.S. Economic Evaluation of Hybrid Energy Systems for Rural Electrification in Six Geo-Political Zones of Nigeria. Renew. Energy 2015, 83, 435-446. [CrossRef]

98. Nandi, S.K.; Ghosh, H.R. Prospect of Wind-PV-Battery Hybrid Power System as an Alternative to Grid Extension in Bangladesh. Energy 2010, 35, 3040-3047. [CrossRef]

99. Sen, R.; Bhattacharyya, S.C. Off-Grid Electricity Generation with Renewable Energy Technologies in India: An Application of HOMER. Renew. Energy 2014, 62, 388-398. [CrossRef]

100. Lau, K.Y.; Yousof, M.F.M.; Arshad, S.N.M.; Anwari, M.; Yatim, A.H.M. Performance Analysis of Hybrid Photovoltaic/Diesel Energy System under Malaysian Conditions. Energy 2010, 35, 3245-3255. [CrossRef]

101. Mohammed, O.H.; Amirat, Y.; Benbouzid, M.E.H.; Feld, G. Optimal Design and Energy Management of a Hybrid Power Generation System Based on Wind/Tidal/PV Sources: Case Study for the Ouessant French Island. In Smart Energy Grid Design for Island Countries: Challenges and Opportunities; Green Energy and Technology; Islam, F.M.R., Mamun, K.A., Amanullah, M.T.O., Eds.; Springer International Publishing: Cham, Switzerland, 2017; pp. 381-413. ISBN 978-3-319-50197-0.

102. Fadaeenejad, M.; Radzi, M.A.M.; AbKadir, M.Z.A.; Hizam, H. Assessment of Hybrid Renewable Power Sources for Rural Electrification in Malaysia. Renew. Sustain. Energy Rev. 2014, 30, 299-305. [CrossRef]

103. Nasri, S.; Sami, B.S.; Cherif, A. Power Management Strategy for Hybrid Autonomous Power System Using Hydrogen Storage. Int. J. Hydrog. Energy 2016, 41, 857-865. [CrossRef]

104. Gan, L.K.; Shek, J.K.H.; Mueller, M.A. Hybrid Wind-Photovoltaic-Diesel-Battery System Sizing Tool Development Using Empirical Approach, Life-Cycle Cost and Performance Analysis: A Case Study in Scotland. Energy Convers. Manag. 2015, 106, 479-494. [CrossRef]

105. Raju, L.; Morais, A.A.; Balaji, V.; Keerthivasan, S. Multi Agent Systems and Arduino Based Smart Micro-Grid Test Bed. AIP Conf. Proc. 2019, 2161, 020032. [CrossRef]

106. Gomes, L.; Vale, Z.; Corchado, J.M. Microgrid Management System Based on a Multi-Agent Approach: An Office Building Pilot. Measurement 2020, 154, 107427. [CrossRef]

107. Merabet, A.; Tawfique Ahmed, K.; Ibrahim, H.; Beguenane, R.; Ghias, A.M.Y.M. Energy Management and Control System for Laboratory Scale Microgrid Based Wind-PV-Battery. IEEE Trans. Sustain. Energy 2017, 8, 145-154. [CrossRef]

108. Chaouachi, A.; Kamel, R.M.; Andoulsi, R.; Nagasaka, K. Multiobjective Intelligent Energy Management for a Microgrid. IEEE Trans. Ind. Electron. 2013, 60, 1688-1699. [CrossRef]

109. Bogaraj, T.; Kanakaraj, J.; Chelladurai, J. Modeling and Simulation of Stand-Alone Hybrid Power System with Fuzzy MPPT for Remote Load Application. Arch. Electr. Eng. 2015, 64, 487-504. [CrossRef] 